\title{
Emerging families of biomarkers for coronary artery disease: inflammatory mediators
}

\author{
This article was published in the following Dove Press journal: \\ Vascular Health and Risk Management \\ 30 July 2013 \\ Number of times this article has been viewed
}

\section{Josef Yayan}

Department of Internal Medicine, University Hospital of Saarland, Homburg/Saar, Germany
Correspondence: Josef Yayan Department of Internal Medicine, University Hospital of Saarland, Kirrberger Straße,

D-6642I Homburg/Saar, Germany

$\mathrm{Tel}+4968411621620$

Fax +49 684II6 23602

Email josef.yayan@hotmail.com
Introduction: Inflammation has been implicated in the development of atherosclerosis in patients with acute coronary syndrome. C-reactive protein is an established nonspecific prognostic inflammatory biomarker for patients with acute coronary syndrome in the medical literature. This has led to a concerted effort to identify circulating inflammatory biomarkers to facilitate predicting the risk for and diagnosing coronary artery disease in at-risk subjects. The objective of this study was to search after novel inflammatory biomarkers reported as useful for diagnosing coronary artery disease.

Methods: The PubMed database was searched for reports published from January 1, 2000 to June 30, 2012 of novel circulating biomarkers for coronary artery disease in addition to the established biomarker, C-reactive protein. The search terms used were "infarction", "biomarkers", and "markers", and only original articles describing clinical trials that were written in English were included. All published articles were separately examined carefully after novel inflammatory markers for acute coronary syndrome. All irrelevant publications without content pertaining to inflammatory biomarkers for acute coronary syndrome were excluded from this study. Our results reflect all articles concerning biomarkers in humans.

Results: The PubMed search yielded 4,415 research articles. After further analysis, all relevant published original articles examining 53 biomarkers were included in this review, which identified 46 inflammation biomarkers useful for detecting coronary artery disease.

Conclusion: The emergence of diverse novel biomarkers for coronary artery disease has provided insight into the varied pathophysiology of this disease. Inflammatory biomarkers have tremendous potential in aiding the prediction of acute coronary syndrome and recurrent ischemic episodes, and will eventually help improve patient care and management.

Keywords: arteriosclerosis, biomarkers, coronary artery disease, myocardial infarction, inflammation, markers

\section{Introduction}

Motivated by the challenge of assessing risk in a heterogeneous population, and guided by advances in our understanding of the pathophysiology of atherosclerosis, investigators and clinicians remain interested in the development and application of novel biomarkers for risk stratification of patients with ST-segment elevation myocardial infarction (STEMI), non-ST elevation myocardial infarction (NSTEMI), and unstable angina (UA). ${ }^{1}$

Coronary angiography must be performed as quickly as possible in patients at high risk, such as those with acute coronary syndrome (ACS). Clinical results can be optimized by combining coronary revascularization with aggressive medical therapy including antiplatelet agents, anticoagulants, and lipid-lowering drugs. 
Although several large-scale randomized controlled trials have rapidly improved the evidence-based guidelines for the management of ACS, doctors often have difficulty determining which of the recommended therapeutic strategies to use in a particular case. These limitations have led investigators to search for circulating biomarkers that can accurately establish a diagnosis of coronary artery disease and thereby speed appropriate triage. ${ }^{2,3}$

The success and usefulness of biomarkers has inspired intense research in this field, resulting in the emergence of several novel, clinically useful biomarkers for ACS and, in turn, a search for circulating markers that will improve the early triage of patients with coronary artery disease and identify those most susceptible to ACS. ${ }^{2}$ Comparative evaluation of newer biomarkers is necessary to determine which are most suitable for integration into present strategies. ${ }^{1}$

In addition, the weak associations of several newer markers with recurrent myocardial infarction (MI) indicate an urgent need for proper assessment of these relationships. Strategies that combine multiple biomarkers and thus reflect the contributions of diverse pathological effectors of ACS may be especially useful for enhancing risk assessment and more effectively targeting therapy. ${ }^{4}$

Several markers of acute MI (AMI) have been identified, but these markers have not been able to improve treatment outcomes because lack of adequate studies with positive results. ${ }^{5}$ Many of these inflammatory markers were not considered for routine use of risk evaluation for coronary artery disease because of a lack of measurement standardization, missing regularity in epidemiological results from prospective studies with endpoints, and failure of evidence that the novel biomarker adds to risk prediction over and above that already achievable through the use of traditional risk factors. ${ }^{6}$

Two strategies for improving the prognosis for ACS patients are currently under investigation: the evaluation of new families of compounds and the use of combinations of multiple biomarkers. Thus, a search for novel biomarkers for acute coronary heart syndrome was performed in order to evaluate the role of biomarkers in risk stratification of patients. Inflammatory mediators have emerged as promising predictors of the risk for ACS, and vascular inflammation reportedly plays a critical role in the pathogenesis of coronary artery disease.

This review is the first comprehensive survey of all inflammatory mediators reported to predict single or repetitive ischemic episodes and their potential for contributing to defined biomarker profiles for assessing the risk for coronary artery disease.

\section{Pathophysiology of coronary artery disease}

A brief overview of the pathophysiology of coronary artery disease is necessary to explain the classification of inflammatory biomarkers (Figure 1). Understanding the pathophysiology of atherosclerosis and the molecular events implicated in the progression from subclinical to overt disease has facilitated the development of cardiovascular disease biomarkers. ${ }^{7,8}$

Arteriosclerotic lesions in the coronary vessels contain abundant macrophages that secrete lytic enzymes such as metalloproteinases. These macrophages are also associated with a reduction in smooth muscle thickness in coronary vessels, low-grade stenosis, and thin fibrous cap. Plaque rupture releases soluble CD40 ligand (sCD40L), placental growth factor (PIGF), pregnancy-associated plasma protein A (PAPP-A), and adhesion molecules. The circulating levels of D-dimers, plasminogen activator inhibitor-1, and von Willebrand factor increase with thrombus formation. Albumin is released after a few hours after thrombus formation, but before the initiation of coronary ischemia. Myocardial necrosis is associated with the time-dependent release of myocyte components such as troponin, myoglobin, and creatine kinase-MB (CK-MB). ${ }^{9}$ Both myocyte necrosis and intracoronary thrombus or distal microembolization of platelet microaggregates contribute to the level of troponin. ${ }^{10}$

\section{Acute-phase response proteins}

Coronary plaque disruption with consequent platelet aggregation and thrombosis is the most important mechanism by which atherosclerosis leads to the acute ischemic syndromes of UA, AMI, and sudden death. ${ }^{11}$ Inflammation is essential to the initiation, development, and progression of atherosclerosis. The association of increased serum levels of acute-phase proteins with the progression of atherosclerosis and occurrence of atherosclerosis-related adverse events, such as coronary artery disease and MI, has been well documented epidemiologically. ${ }^{12-31}$ These acute-phase protein markers include serum C-reactive protein (CRP), pentraxin 3 (PTX3), amyloid A, homocysteine, and fibrinogen. ${ }^{12-45}$

\section{C-reactive protein}

Elevated concentrations of the acute-phase protein CRP have been reported in association with both UA and AMI. ${ }^{12-15}$ Liuzzo et a ${ }^{15}$ showed that CRP and serum amyloid A concentrations increase independently of myocardial cell injury in patients with UA. CRP has been shown to predict risk in a wide variety of clinical settings and has 


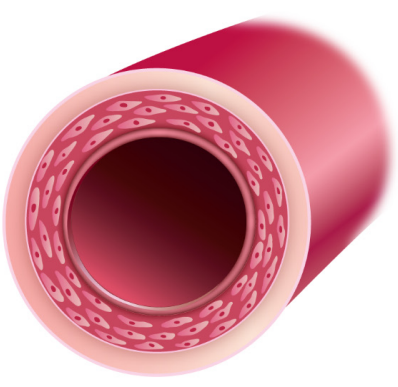

Coronary artery

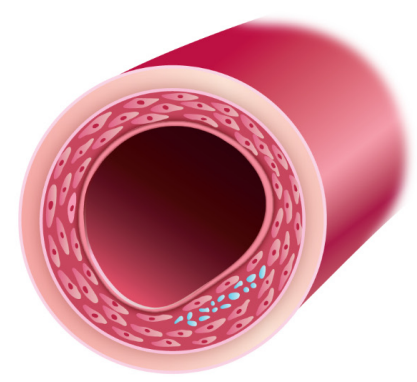

Macrophages secrete metalloproteinases

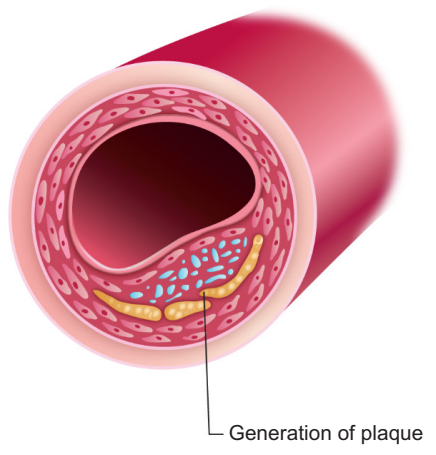

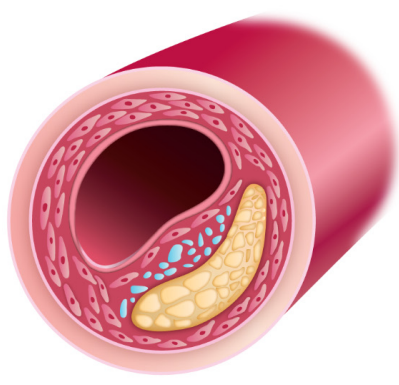

Low grade stenosis

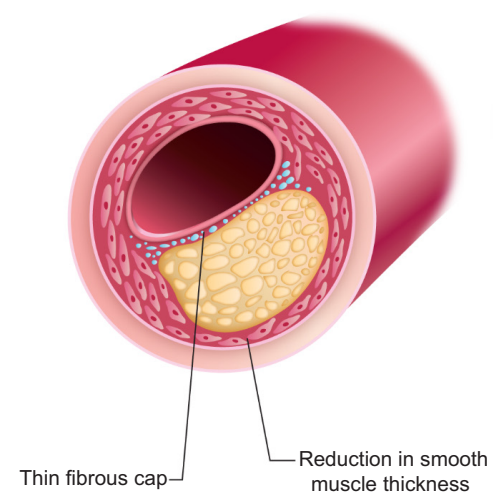

Thin fibrous capmuscle thickness

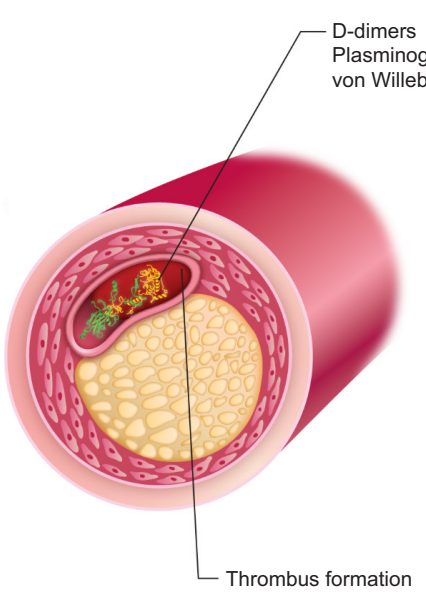

Figure I Pathophysiology of coronary artery disease.

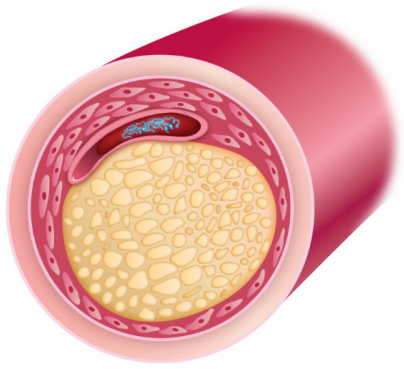

Albumin is released before initiation of coronary ischemia

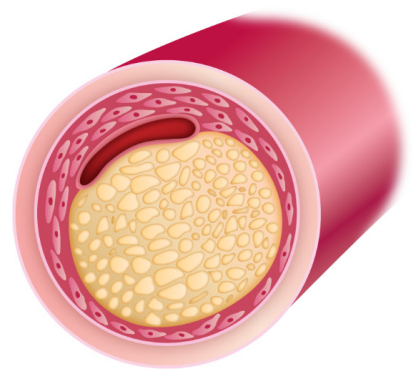

Final stage of coronary ischemia incremental value over standard lipid screening for primary prevention. ${ }^{16-18} \mathrm{~A}$ recent analysis by Chew et a ${ }^{19}$ showed that the CRP level predicts the risk for death or MI within 30 days among patients undergoing percutaneous coronary intervention (PCI) ${ }^{20-22} \mathrm{CRP}$ has been suggested to indicate generalized inflammation and participates directly and actively in both atherogenesis and atheromatous plaque disruption (Table 1) ${ }^{23-25}$ However, there is no strong evidence for the direct involvement of CRP in ACS.

\section{Pentraxin 3}

PTX3, an inflammatory biomarker involved in acute-phase responses in the blood, is believed to be more specific for vascular inflammation than CRP. It is currently unclear whether 
Table I Acute-phase response proteins

\begin{tabular}{|c|c|c|c|c|c|}
\hline & \multicolumn{5}{|c|}{ Acute-phase response proteins } \\
\hline & C-reactive protein & Pentraxin 3 & Homocysteine & Amyloid A & Fibrinogen \\
\hline Origin & $\begin{array}{l}\text { Protein } \\
\text { Liver }\end{array}$ & $\begin{array}{l}\text { Protein } \\
\text { Several cell types: } \\
\text { mononuclear phagocytes, } \\
\text { dendritic cells, fibroblasts, } \\
\text { endothelial cells }\end{array}$ & $\begin{array}{l}\text { Nonprotein amino acid } \\
\text { Metabolic origin in the } \\
\text { blood }\end{array}$ & $\begin{array}{l}\text { Apolipoprotein } \\
\text { Liver }\end{array}$ & $\begin{array}{l}\text { Plasma glycoprotein } \\
\text { Liver }\end{array}$ \\
\hline $\begin{array}{l}\text { Normal serum } \\
\text { concentration }\end{array}$ & $<5 \mathrm{mg} / \mathrm{L}$ & $5-10 \mu \mathrm{mol} / \mathrm{L}$ & $<15 \mu \mathrm{mol} / \mathrm{L}$ & $<325 \mu \mathrm{g} / \mathrm{L}$ & $180-400 \mathrm{mg} / \mathrm{dL}$ \\
\hline Mean cut-off value & $>3.0 \mathrm{mg} / \mathrm{L}$ & $\begin{array}{l}\mathrm{I} .7 \mathrm{I} \pm \mathrm{I} .88 \mathrm{ng} / \mathrm{mL} ; \\
P=0.00 \mathrm{I}\end{array}$ & $\begin{array}{l}20.2 \pm 14.3 \mu \mathrm{mol} / \mathrm{L} ; \\
P<0.00 \mathrm{I}\end{array}$ & $>325 \mu \mathrm{g} / \mathrm{L}$ & $>450 \mathrm{mg} / \mathrm{dL}$ \\
\hline Predicts & $\begin{array}{l}\text { Atherogenesis, } \\
\text { atherosclerosis, } \\
\text { unstable angina, acute } \\
\text { myocardial infarction, } \\
\text { death, recurrence of } \\
\text { cardiovascular events }\end{array}$ & $\begin{array}{l}\text { Vascular inflammation, } \\
\text { STEMI, NSTEMI, angina } \\
\text { pectoris, death, heart } \\
\text { failure }\end{array}$ & $\begin{array}{l}\text { Thrombosis, myocardial } \\
\text { injury, heart failure, } \\
\text { cardiovascular disease }\end{array}$ & $\begin{array}{l}\text { ACS, NSTEMI, } \\
\text { ventricular systolic } \\
\text { dysfunction, death }\end{array}$ & $\begin{array}{l}\text { Myocardial } \\
\text { infarction, mortality }\end{array}$ \\
\hline Clinical relevance & $\begin{array}{l}\text { Screening for primary } \\
\text { prevention, diagnostic } \\
\text { marker for CAD, } \\
\text { prognostic marker } \\
\text { for CAD }\end{array}$ & $\begin{array}{l}\text { Vascular inflammation, } \\
\text { diagnostic marker for } \\
\text { CAD, prognostic marker } \\
\text { for CAD }\end{array}$ & Cardiovascular risk & $\begin{array}{l}\text { NSTEMI in coronary } \\
\text { artery disease, } \\
\text { diagnostic marker } \\
\text { for CAD, prognostic } \\
\text { marker for CAD }\end{array}$ & $\begin{array}{l}\text { Recurrence } \\
\text { of myocardial } \\
\text { infarction, } \\
\text { prognostic marker } \\
\text { for CAD }\end{array}$ \\
\hline $\begin{array}{l}\text { Statistical } \\
\text { association between } \\
\text { biomarker and } \\
\text { myocardial infarction }\end{array}$ & $\begin{array}{l}\mathrm{OR}=3.68 \\
95 \% \mathrm{Cl}=1.5 \mathrm{I}-8.99 \\
P=0.004\end{array}$ & $\begin{array}{l}\mathrm{HR}=0.96 \\
95 \% \mathrm{Cl}=0.8 \mathrm{I}-1.2 \mathrm{I}\end{array}$ & & $\mathrm{OR}=1.95, P=0.038$ & \\
\hline $\begin{array}{l}\text { Statistical association } \\
\text { between biomarker } \\
\text { and angina }\end{array}$ & & $\begin{array}{l}\mathrm{HR}=\mathrm{I} .09 \\
95 \% \mathrm{Cl}=0.98-1.20\end{array}$ & & $\mathrm{OR}=1.86, P=0.044$ & \\
\hline $\begin{array}{l}\text { Statistical association } \\
\text { between biomarker } \\
\text { and CAD }\end{array}$ & & & $\begin{array}{l}\mathrm{OR}=2.05, \\
95 \% \mathrm{Cl}=1.56-2.54, \\
P<0.005\end{array}$ & & $r=0.213, P<0.05$ \\
\hline $\begin{array}{l}\text { Statistical association } \\
\text { between biomarker } \\
\text { and death }\end{array}$ & $\begin{array}{l}\mathrm{RR}=1.9,95 \% \\
\mathrm{Cl}=1.2-3.1\end{array}$ & $\begin{array}{l}\mathrm{HR}=\mathrm{I} . \mathrm{II} \\
95 \% \mathrm{Cl}=1.02-1.2 \mathrm{I}\end{array}$ & & $\begin{array}{l}\mathrm{RR}=5.8 \\
95 \% \mathrm{Cl}=\mathrm{I} .3-27.7\end{array}$ & \\
\hline References & $12-25$ & $30-36$ & $37-39$ & $40-42$ & $43-45$ \\
\hline
\end{tabular}

Abbreviations: STEMI, ST-segment elevation myocardial infarction; NSTEMI, non-ST-elevation myocardial infarction; ACS, acute coronary syndrome; CAD, coronary artery disease; OR, odds ratio; $\mathrm{Cl}$, confidence interval; $\mathrm{HR}$, hazard ratio; RR, risk ratio; $r$, Pearson correlation coefficient.

the association of PTX3 with adverse events in individuals with stable coronary artery disease is independent of kidney dysfunction. In subjects with stable coronary artery disease, higher PTX3 concentrations were associated independently of systemic inflammation with increased risk for all-cause mortality, cardiovascular events, and incident heart failure. Adjustment for the estimated glomerular filtration rate modestly attenuated these associations, suggesting that future studies of PTX3 should adjust for kidney function (Table 1). ${ }^{33-36}$

\section{Homocysteine}

A recently published study evaluated the association between elevated serum homocysteine levels and elevated serum troponin I ( $\mathrm{TnI}$ ) levels as an alternative biomarker for myocardial injury. ${ }^{37}$ In this cross-sectional study of patients with
AMI, high serum homocysteine concentrations were associated with a high frequency of thrombosis; more significantly, an elevated plasma homocysteine level was positively associated with an elevated plasma TnI level. Therefore, the plasma level of homocysteine was related to the degree of myocardial injury as assessed by the plasma TnI level. ${ }^{37}$

Heart failure is an important determinant of the clinical outcome after AMI. The plasma homocysteine level was evaluated as a predictor of heart failure in patients with AMI in a series of patients with AMI without renal failure. The authors of this study noted that the serum homocysteine level may be related to the progression of heart failure in patients with AMI. ${ }^{38}$

Recent studies have shown elevated plasma homocysteine concentrations to be associated with higher risk for more 
severe vascular disease. Furthermore, an elevated serum level of homocysteine has been shown to be a major predictor of cardiovascular disease. These results indicated a positive association between the serum level of homocysteine and the degree of coronary injury, and the results further suggested a role for homocysteine in the evaluation of cardiovascular risk in clinical practice (Table 1). ${ }^{39}$

\section{Amyloid A}

Elevated serum levels of CRP are believed to indicate higher risk for cardiovascular events in patients with ACS. However, amyloid A may be an important inflammatory biomarker for the detection of coronary artery disease, as well as a prognostic factor. To elucidate this connection between amyloid $\mathrm{A}$ and CRP, Kosuge et $\mathrm{al}^{40}$ examined patients with ACS. Elevation of the level of amyloid A was associated with cardiovascular events within 30 days after ACS regardless of the level of CRP. Therefore, amyloid A was a more useful predictor than CRP in these patients with ACS (Table 1).

This association between the plasma level of amyloid A and AMI was also examined in another study. The left ventricular ejection fraction (LVEF) measured during follow-up was significantly lower in the high serum amyloid A group than in the low serum amyloid A group. Many complications such as cardiac rupture, carcinogenic shock, subacute thrombosis, and cardiac death occurred at significantly higher rates in the high serum amyloid A group than in the low serum amyloid group. ${ }^{41}$

The results showed that the amyloid $A$ and high-sensitivity CRP (hs-CRP) levels were linked with a large number of cardiovascular risk factors. In comparison with the other risk factors, the level of amyloid A was relatively well associated with coronary artery disease and was highly predictive of the risk for cardiovascular events within 3 years, while the level of hs-CRP was not associated with cardiovascular heart disease. In addition, the amyloid A level was a powerful predictor of adverse cardiovascular events. ${ }^{42}$

\section{Fibrinogen}

Fibrinogen plays a key function in platelet aggregation via the formation of fibrin and is a major determinant of plasma viscosity and erythrocyte aggregation. Both constitutively expressed and inducible fibrinogen are present during the acute-phase response. Some studies have found associations between elevated plasma fibrinogen levels and increased risk for coronary artery disease and MI. ${ }^{43,44}$ Although no agents specifically reduce fibrinogen levels, some agents that decrease the level of cholesterol or inflammation also decrease the level of fibrinogen. Polymorphisms in the human fibrinogen gene associated with elevated fibrinogen levels do not increase the risk for MI. These findings led to the discovery that fibrinogen is a biomarker for coronary artery disease. ${ }^{43,44}$

While several studies have found fibrinogen to be an independent risk factor for coronary artery disease, ${ }^{43,44}$ the significance of the fibrinogen level assessed during AMI for future fatal or nonfatal cardiovascular events remains controversial. To address this question, age, body mass index (BMI), systolic blood pressure, smoking history, ejection fraction, plasma levels of total cholesterol, triglycerides, fibrinogen, and glucose, as well as white blood cell parameters were assessed in male patients with MI. The plasma fibrinogen level was the only independent predictor of mortality and MI in this study. Moreover, both these results and other observations from recent studies suggest that evaluation of the fibrinogen level during MI could be useful for identifying patients at higher risk for future acute cardiovascular events (Table 1). ${ }^{45}$

\section{Blood cells}

\section{Erythrocyte sedimentation rate}

A very recent study examined the potential usefulness of the erythrocyte sedimentation rate as a supplemental marker for coronary artery disease. Patients with angina pectoris or MI who underwent coronary angiography were enrolled in the study, while patients without coronary artery disease served as a control group. The sensitivity and specificity of the erythrocyte sedimentation rate for coronary artery disease were $67.65 \%$ and $70.59 \%$, respectively. Therefore, the erythrocyte sedimentation rate may be a helpful supplemental diagnostic test for coronary artery disease. ${ }^{46}$

Of the factors examined in another study, only elevation of the erythrocyte sedimentation rate was associated with higher rates of noncoronary artery disease death and nonfatal MI. Therefore, the erythrocyte sedimentation rate was a potent predictor of coronary artery disease mortality. The erythrocyte sedimentation rate may provide considerable information on the risk of death from coronary artery disease beyond that conveyed by the fibrinogen level (Table 2). ${ }^{47,48}$

\section{Monocytes}

The value of a coordinated inflammatory response in patients with STEMI has been neglected for years. Monocytes perform important functions in the inflammatory process in these patients; therefore, the relationship between the inflammatory roles of monocytes and MI was recently studied. ${ }^{49}$ This study 
Table 2 Blood cells

\begin{tabular}{|c|c|c|c|c|c|}
\hline & \multicolumn{5}{|l|}{ Blood cells } \\
\hline & $\begin{array}{l}\text { Erythrocyte } \\
\text { sedimentation rate }\end{array}$ & Monocytes & Leukocytes & Soluble CD40 ligand & Neutrophils \\
\hline Origin & Red blood cells & $\begin{array}{l}\text { Stem cells in the } \\
\text { bone marrow }\end{array}$ & $\begin{array}{l}\text { Multipotent cells } \\
\text { in the bone marrow }\end{array}$ & Platelets & $\begin{array}{l}\text { Stem cells in the } \\
\text { bone marrow }\end{array}$ \\
\hline Normal serum value & $\begin{array}{l}<10 \mathrm{~mm} \text { in the } 1 \mathrm{st} \\
\text { hour } \\
<20 \mathrm{~mm} \text { in the } 2 \mathrm{nd} \\
\text { hour }\end{array}$ & $\begin{array}{l}<0.8 \times 10^{9} / \mathrm{L} \\
(2 \%-10 \% \text { of white } \\
\text { blood cells })\end{array}$ & $<5.9 \times 10^{9} / \mathrm{L}$ & $<7,107 \mathrm{pg} / \mathrm{mL}$ & $2.7-7.5 \times 10^{9} / \mathrm{L}$ \\
\hline Mean cut-off value & $\begin{array}{l}>10 \mathrm{~mm} \text { in the } 1 \mathrm{st} \\
\text { hour } \\
>20 \mathrm{~mm} \text { in the } 2 \mathrm{nd} \\
\text { hour }\end{array}$ & $\begin{array}{l}>0.8 \times 10^{9} / \mathrm{L} \\
(2 \%-10 \% \text { of white } \\
\text { blood cells })\end{array}$ & $>8.2 \times 10^{9} / \mathrm{L}$ & $>7,107 \mathrm{pg} / \mathrm{mL}$ & $6.7 \times 10^{9} / \mathrm{L}$ \\
\hline Predicts & CAD & $\begin{array}{l}\text { STEMI, left } \\
\text { ventricular ejection } \\
\text { fraction, infarct size, } \\
\text { microvascular } \\
\text { obstruction, poor } \\
\text { functional outcome }\end{array}$ & $\begin{array}{l}\text { Myocardial infarction, } \\
\text { ischemic stroke }\end{array}$ & $\begin{array}{l}\text { Cardiovascular disease, } \\
\text { adverse events during } \\
\text { the hospital stay, } \\
\text { recurrence of } \\
\text { myocardial infarction, } \\
\text { ACS }\end{array}$ & $\begin{array}{l}\text { Myocardial } \\
\text { infarction, mortality, } \\
\text { unstable angina }\end{array}$ \\
\hline Clinical relevance & $\begin{array}{l}\text { CAD, diagnostic } \\
\text { marker for CAD }\end{array}$ & $\begin{array}{l}\text { Myocardial injury, } \\
\text { diagnostic marker } \\
\text { for CAD }\end{array}$ & $\begin{array}{l}\text { Ischemic disease, } \\
\text { diagnostic marker } \\
\text { for CAD }\end{array}$ & $\begin{array}{l}\text { Diagnostic marker } \\
\text { for CAD, prognostic } \\
\text { marker for CAD }\end{array}$ & $\begin{array}{l}\text { Diagnostic marker } \\
\text { for CAD, prognostic } \\
\text { marker for CAD }\end{array}$ \\
\hline $\begin{array}{l}\text { Statistical association } \\
\text { between biomarker } \\
\text { and myocardial infarction }\end{array}$ & & $\begin{array}{l}\mathrm{HR}=0.96 \\
95 \% \mathrm{Cl}=0.8 \mathrm{I}-\mid .2 \mathrm{I}\end{array}$ & $\mathrm{RR}=1.56, P<0.00 \mathrm{I}$ & $\begin{array}{l}\mathrm{OR}=\mathrm{I} .66 \\
95 \% \mathrm{Cl}=0.56-4.87\end{array}$ & \\
\hline $\begin{array}{l}\text { Statistical association } \\
\text { between biomarker } \\
\text { and angina }\end{array}$ & & $\begin{array}{l}\mathrm{HR}=\mathrm{I} .09 \\
95 \% \mathrm{Cl}=0.98-\mathrm{I} .20\end{array}$ & & & \\
\hline $\begin{array}{l}\text { Statistical association } \\
\text { between biomarker } \\
\text { and CAD }\end{array}$ & $\begin{array}{l}95 \% \mathrm{Cl}=42.34-59.14 \\
67.65 \% \text { sensitivity; } \\
70.59 \% \text { specificity }\end{array}$ & $\begin{array}{l}95 \% \\
\mathrm{Cl}=42.34 \%-59.14 \%\end{array}$ & & & \\
\hline $\begin{array}{l}\text { Statistical association } \\
\text { between biomarker } \\
\text { and death }\end{array}$ & $\mathrm{OR}=3.3 ; P<0.01$ & $\begin{array}{l}\mathrm{HR}=\mathrm{I} . \mathrm{II}, 95 \% \\
\mathrm{Cl}=\mathrm{I} .02-1.21\end{array}$ & $\mathrm{RR}=\mathrm{I} .5 \mathrm{I}, \mathrm{P}<0.00 \mathrm{I}$ & & $\begin{array}{l}\mathrm{HR}=2.47 \\
95 \% \mathrm{Cl}=\mathrm{I} .63-3.72\end{array}$ \\
\hline References & $46-48$ & 49 & $53-56$ & $50-52$ & $57-59$ \\
\hline
\end{tabular}

Abbreviations: STEMI, ST-segment elevation myocardial infarction; ACS, acute coronary syndrome; CAD, coronary artery disease; HR, hazard ratio; CI, confidence interval; RR, risk ratio; OR, odds ratio.

showed an association of a proinflammatory monocyte response characterized by high levels of classical monocytes with severe myocardial injury and poor functional outcome after STEMI. Further studies are required to investigate the biologic nature and therapeutic implications of this association (Table 2).

\section{Soluble CD40 ligand}

The binding of the CD40 ligand (CD40L) to CD40 induces inflammatory processes that permit the secretion of proinflammatory cytokines. Elevated levels of CD40L have been found in patients with hypercholesterolemia and ACS. New data show that high levels of SCD40L predict cardiovascular disease (Table 2). Recent research into the possible influence of genetic variability on the regulation of CD40L and the inflammatory process in coronary artery disease is of great interest. ${ }^{50}$ Furthermore, various pharmaceutical experiments with statins, antihypertensive drugs, and antiplatelet agents have shown that modulation of the serum level of CD40L in patients with ACS is associated with positive outcomes. Further studies are required to elucidate the role of the CD40/CD40L system in the pathogenesis of coronary artery disease.

The blood CD40L levels of all patients were measured using an enzyme-linked immunosorbent assay. The serum concentration of CD40L was examined with respect to events such as recurrent MI, acute cardiac insufficiency, carcinogenic shock, and death. ${ }^{51}$ However, elevated levels of CD40L in patients with ACS were not associated with a significantly increased risk for an in-hospital adverse event.

The serum level of CD40L was found to be higher in smokers, negatively associated with lung function, 
and positively associated with both total cholesterol and biomarkers of inflammation, but not with other common cardiovascular risk factors. In addition, the geometrical mean levels of CD40L were similar between the control group and patients with MI. Therefore, CD40L was related to various inflammatory biomarkers and was not an independent biomarker for the risk of MI. ${ }^{52}$

\section{Leukocytes}

Leukocytosis is often caused by infection or inflammation, while diseases of the bone marrow are much rarer but more problematic causes. The bone marrow responds to inflammation or infection by releasing leukocytes; physical and psychological stress can also cause leukocyte release, as can corticosteroids, lithium, and beta agonists. Allergic reactions specifically increase eosinophil or basophil counts. Marrow diseases should be considered first in cases of leukocytosis. Weight loss; hemorrhage; hematomas; liver, spleen, or lymph node enlargement; and immunosuppression increase the index of suspicion for a marrow disorder. The majority of bone marrow diseases are classified as acute leukemia, chronic leukemia, or myeloproliferative disease. While acute leukemia is usually diagnosed in the acute phase, chronic leukemia is often discovered only incidentally (Table 2). ${ }^{53}$

Leukocytes were examined as a marker for coronary artery disease in patients with ischemic stroke, MI, or peripheral arterial disease. The patients were randomized to receive aspirin or clopidogrel, and their incidence rates of ischemic stroke, MI, and vascular death were compared. The number of neutrophils was the greatest contributor to the increased risk. Treatment with aspirin versus clopidogrel did not influence the predictive value of the leukocyte count. The number of leukocytes became elevated significantly over the upper limit of the reference range 1 week before the recurrent event. ${ }^{54}$ This study found that the levels of leukocytes and especially neutrophils were independently associated with ischemic circulatory disorders in this high-risk patient population, and that an elevated leukocyte count indicated increased risk for an ischemic event for the following 1 week.

The relationship between leukocytes and N-terminal pro-brain natriuretic peptide (NT-proBNP) and its prognostic significance was studied in patients with ACS. Statistical analysis showed no statistically significant association between the leukocyte count and ACS, although high leukocyte counts were often found in patients with elevated NT-proBNP levels. Further studies are required to clarify this issue..$^{55}$

Human leukocyte antigens (HLAs) are located on the surface of leukocytes. HLAs serve for presentation of antigen.
The association between HLA type and cardiovascular disease was examined in large cohorts of patients with AMI and healthy controls. This study showed that associations between HLA-DRB1 and DQA1 loci and coronary artery disease exists. The HLA-DRB1 and DQA1 were detected with an increased risk for AMI. ${ }^{56}$

\section{Neutrophils}

Neutrophils are involved in thrombus formation. Specific features of neutrophil activation were compared among patients with ACS, stable angina, and systemic inflammatory diseases. Neutrophils are rapidly released into the circulation during periods of acute stress, such as trauma or AMI. Increased neutrophil counts have been hypothesized to add incremental value to the early diagnosis of and stratification of risk for AMI. A prospective, observational, multicenter study investigated the diagnostic accuracy of a combination of the neutrophil count and level of TnT in patients with symptoms suggestive of AMI. It was noted that the neutrophil count does not improve the rate of early diagnosis of AMI in patients presenting with chest pain, but does identify patients at increased risk for death. ${ }^{57}$

The myeloperoxidase (MPO) content of circulating neutrophils was determined by flow cytometry in patients with ACS, chronic stable angina, and inflammation due to either noninfectious, infectious, or autoimmune disease. A complete MPO depletion was observed during the first 4 hours after the onset of symptoms in neutrophils in patients with STEMI and of those with NSTEMI, respectively - a phenotype not observed in any other group of patients. MPO depletion was associated with platelet activation, as indicated by $\mathrm{P}$-selectin expression, activation, and transactivation of leukocyte $\beta 2$-integrins, and the formation of platelet-neutrophil and platelet-monocyte aggregates. ACS, like other systemic inflammatory syndromes, is characterized by intense neutrophil activation. In the very early phase of AMI, only a subpopulation of neutrophils is massively activated, possibly via platelet-P selectin interactions. This paroxysmal activation could contribute to occlusive thrombosis. ${ }^{58}$

The role of inflammation was investigated by measuring the activation of circulating platelets and neutrophils by inflammatory processes, as indicated by expression of $\mathrm{P}$-selectin in platelets and CD11b in neutrophils, and by the formation of neutrophil-platelet aggregates, by flow cytometry, in anticoagulated peripheral venous blood from patients with UA and stable angina. The authors ${ }^{59}$ found that the circulating levels of activated platelets and neutrophils were elevated in patients with UA, especially during the acute phase. These findings 
also suggest the known fact that thrombus formation occurs after the rupture of atherosclerotic plaques and the subsequent induction of inflammation (Table 2). ${ }^{59}$

\section{Biomarkers of plaque instability}

AMI is caused by plaque erosion and rupture. Markers of plaque instability may be useful in the early diagnosis of AMI and the risk stratification of patients. Four biomarkers of plaque instability - MPO, myeloid-related protein 8/14 (MRP-8/14), PAPP-A, and CRP - were examined in consecutive patients who presented with acute chest pain, and their levels were compared with those of healthy subjects and subjects with high-sensitivity cTnT (hs-cTnT). Interestingly, the concentrations of all biomarkers were significantly increased in patients with AMI in this study; however, these concentrations were smaller than hs-cTnT. The concentrations of MPO, MRP-8/14, and CRP were increased in the deceased. Therefore, biomarkers of plaque instability predicted allcause mortality with moderate precision in this study. ${ }^{60}$

\section{Myeloperoxidase}

Activation of neutrophils leads to the release of MPO, which is regarded as a marker for plaque vulnerability in patients with ACS. The association between MPO and ACS has been clarified in several published studies. ${ }^{60-62}$

The level of MPO in patients with STEMI treated by PCI has not yet been established as a prognostic factor for coronary artery disease. Therefore, a study was conducted in patients with STEMI who had undergone primary PCI. The plasma MPO level independently predicts in-hospital mortality in patients with STEMI treated by PCI (Table 3$){ }^{63}$

\section{Myeloid-related protein $8 / 14$}

Elevation of the concentration of MRP-8/14 in apparently healthy individuals is associated with higher risk for future cardiovascular events, but this parameter has not been assessed for prognostic significance in patients with ACS. A nested case-control study examined the risk of cardiovascular death or MI in relation to the level of MRP-8/14 measured 30 days after an episode of ACS. MRP-8/14 was found to be a useful biomarker of platelet and inflammatory disease activity associated with atherothrombosis, and it may also be a promising novel target for therapeutic intervention (Table 3). ${ }^{64}$

\section{PAPP-A}

PAPP-A is a high-molecular-weight zinc-binding metalloproteinase. Bonaca et $\mathrm{al}^{65}$ investigated the usefulness of

Table 3 Biomarkers of plaque instability

\begin{tabular}{|c|c|c|c|c|}
\hline & \multicolumn{4}{|c|}{ Biomarkers of plaque instability } \\
\hline & Myeloperoxidase & $\begin{array}{l}\text { Myeloid-related } \\
\text { protein } 8 / 14\end{array}$ & $\begin{array}{l}\text { Pregnancy- } \\
\text { associated plasma } \\
\text { protein } A\end{array}$ & $\begin{array}{l}\text { Soluble lectin-like } \\
\text { oxidized low-density } \\
\text { lipoprotein receptor-I }\end{array}$ \\
\hline Origin & $\begin{array}{l}\text { Hemoprotein stored in } \\
\text { neurophil granules }\end{array}$ & $\begin{array}{l}\text { Protein produced in } \\
\text { myeloid cells }\end{array}$ & $\begin{array}{l}\text { Metalloproteinase of } \\
\text { placental origin }\end{array}$ & $\begin{array}{l}\text { Cell-surface receptor in } \\
\text { vascular endothelial cells }\end{array}$ \\
\hline Normal serum concentration & $<840 \mathrm{pmol} / \mathrm{L}$ & $1.9-2.8 \mathrm{mg} / \mathrm{L}$ & $<6.0 \mu \mathrm{IU} / \mathrm{mL}$ & $<91.0 \mathrm{pg} / \mathrm{mL}$ \\
\hline Mean cutoff value & $>840 \mathrm{pmol} / \mathrm{L}$ & $>5.6 \mathrm{mg} / \mathrm{L}$ & $>6.0 \mu \mathrm{IU} / \mathrm{mL}$ & $>91.0 \mathrm{pg} / \mathrm{mL}$ \\
\hline Predicts & STEMI, in-hospital mortality & $\begin{array}{l}\text { Recurrence of } \\
\text { cardiovascular events, } \\
\text { myocardial infarction, death }\end{array}$ & ACS, NSTEMI, death & STEMI, NSTEMI, ACS \\
\hline Clinical relevance & $\begin{array}{l}\text { In-hospital mortality, } \\
\text { diagnostic marker for CAD, } \\
\text { prognostic marker for CAD }\end{array}$ & $\begin{array}{l}\text { Recurrence of myocardial } \\
\text { infarction, prognostic } \\
\text { marker for CAD }\end{array}$ & $\begin{array}{l}\text { Recurrence of NSTEMI, } \\
\text { prognostic marker } \\
\text { for CAD }\end{array}$ & $\begin{array}{l}\text { STEMI, NSTEMI, } \\
\text { diagnostic marker } \\
\text { for CAD }\end{array}$ \\
\hline Statistical association & & $P=0.020$ & $\mathrm{HR}=\mathrm{I} .82$ & $P<0.0001$ \\
\hline between biomarker and & & & $95 \% \mathrm{Cl}=1.22-2.7 \mathrm{I}$ & $89.6 \%$ sensitivity, \\
\hline myocardial infarction & & & $P=0.003$ & $82.4 \%$ specificity \\
\hline Statistical association between & & & $\mathrm{HR}=\mathrm{I} .94$ & \\
\hline biomarker and angina & & & $\begin{array}{l}95 \% \mathrm{Cl}=\mathrm{I} .07-3.52 \\
P=0.027\end{array}$ & \\
\hline $\begin{array}{l}\text { Statistical association between } \\
\text { biomarker and CAD }\end{array}$ & & & & \\
\hline Statistical association between & $\mathrm{OR}=3.88$ & $\mathrm{OR}=2.1$ & $\mathrm{HR}=2.0 \mathrm{I}$ & \\
\hline biomarker and death & $\begin{array}{l}95 \% \mathrm{Cl}=\mathrm{I} .13-13.34 \\
P=0.03 \mid\end{array}$ & $95 \% \mathrm{Cl}=1.2-3.8$ & $\begin{array}{l}95 \% \mathrm{Cl}=1.43-2.82 \\
P<0.00 \mathrm{I}\end{array}$ & \\
\hline References & $60-63$ & 64 & 65,66 & 68,69 \\
\hline
\end{tabular}

Abbreviations: STEMI, ST-segment elevation myocardial infarction; ACS, acute coronary syndrome; NSTEMI, non-ST-elevation myocardial infarction; CAD, coronary artery disease; HR, hazard ratio; $\mathrm{Cl}$, confidence interval; OR, odds ratio. 
PAPP-A for assessing the risk for subsequent cardiovascular events in patients with ACS. PAPP-A was independently associated with recurrent cardiovascular events in patients with ACS. This finding supported the potential usefulness of PAPP-A as a biomarker in patients with ACS. Another study has suggested PAPP-A to be a predictor of mortality or MI in patients with ACS. ${ }^{66}$

While biomarkers of plaque instability did not appear useful for the early diagnosis of AMI, they may provide some incremental value in the risk stratification of patients with acute chest pain (Table 3). ${ }^{60}$

\section{hs-cTnT with MPO and PAPP-A}

Khan et $a{ }^{67}$ compared the accuracies for the early diagnosis of AMI of the levels of hs-cTnT, MPO, and PAPP-A measured at the time of presentation to the emergency department. The level of hs-cTnT performed better than those of MPO and PAPP-A for the early triage and diagnosis of AMI among patients with coronary artery disease presenting with ACS.

\section{Soluble lectin-like oxidized low-density lipoprotein receptor-I, sLOX-I}

Measurement of the typical cardiospecific cardiac enzymes for the diagnosis of MI is often not very informative due to lack of secretion of these enzymes. The known cardiac enzymes include CK-MB, troponins, myoglobin, and heart-type fatty acid-binding protein (H-FABP). A new marker of plaque vulnerability, soluble lectin-like oxidized low-density lipoprotein receptor-1 (sLOX-1), was recently analyzed in comparison with other markers during the early stages of STEMI. The serum level of sLOX-1 predicted early STEMI more precisely than the levels of H-FABP, myoglobin, TnT, and CK-MB. ${ }^{68}$

Biomarkers of cardiac injury, such as TnT, are used to diagnose acute ACS. However, biomarkers for plaque instability may be more useful for diagnosing ACS in the early stages of MI. sLOX-1 seems to be essential to the pathogenesis of atherosclerotic plaque rupture and the onset of ACS. sLOX-1 is liberated by proteolytic cleavage. The serum level of sLOX-1 was significantly higher in patients with ACS than in the control subjects and was associated with ACS according to multivariable logistic regression analysis. The SLOX-1 level could also differentiate patients with ACS without ST elevation or abnormal Q waves and those with ACS without TnT elevation, from patients without ACS, with $91 \%$ sensitivity and $83 \%$ specificity. In patients with ACS, sLOX-1 identified coronary artery disease earlier than did TnT. These results suggest that sLOX-1 is a useful biomarker for coronary artery disease (Table 3). ${ }^{69}$

\section{Substances involved in lipid metabolism}

\section{Lipoprotein-associated phospholipase A2}

Lipoprotein-associated phospholipase A (Lp-PLA)2 (also known as platelet-activating factor acetylhydrolase) is an enzyme that is secreted into the bloodstream by inflammatory cells. Most circulating Lp-PLA2 is bound to low-density lipoprotein (LDL) and hydrolyzes oxidized phospholipids therein. This enzyme is also known to be atherogenic. Accordingly, a clinical study of patients with ACS showed that coronary angioplasty to remove coronary artery stenosis was associated with reduction in the plasma Lp-PLA2 level, suggesting that Lp-PLA2 could be a marker for ACS. ${ }^{70}$ Lp-PLA2 is a vascular-specific inflammatory enzyme, and elevated Lp-PLA2 activity is associated with cardiovascular events. One study of patients with ACS who had undergone successful PCI precisely determined the plaque volume in non-culprit sites of PCI for lesions by grayscale intravascular ultrasound both at the time of onset and after 6 months. The associations among plaque volume, lipid profiles, and LpPLA2 levels were subsequently analyzed. ${ }^{70}$

The relationship between Lp-PLA2 and endothelial dysfunction, an early manifestation of atherosclerosis, was examined in another cohort study that enrolled subjects without known clinical cardiovascular disease. In summary, Lp-PLA2 was not associated with endothelial dysfunction, suggesting that its role in the development of atherosclerosis is primarily related to other, unspecified factors. ${ }^{71}$

The association between circulating Lp-PLA2 and vascular disease is independent of other risk factors. The Lp-PLA2 activity and mass, lipid content, and additional characteristics were measured at baseline and during followup of 5 years in a randomized trial of subjects at high risk for developing vascular disease who were treated with simvastatin. In summary, the association between Lp-PLA2 and occlusive coronary events depended considerably upon lipid levels, whereas those between Lp-PLA2 and other cardiac events appeared to reflect confounding variables associated with cardiovascular medication and prior vascular disease (Table 4). ${ }^{72}$

Many studies have been published on the role of LpPLA2 in atherosclerosis. ${ }^{71,72}$ Mallat et $\mathrm{al}^{73}$ also reported a positive association between high plasma levels of Lp-PLA2 
Table 4 Substances involved in lipid metabolism

\begin{tabular}{|c|c|c|c|}
\hline & \multicolumn{3}{|c|}{ Substances involved in lipid metabolism } \\
\hline & $\begin{array}{l}\text { Lipoprotein-associated } \\
\text { phospholipase A2 }\end{array}$ & Lysophosphatidylcholine & Galectin-3 \\
\hline Origin & $\begin{array}{l}\text { Inflammatory enzyme expressed } \\
\text { in atherosclerotic plaques }\end{array}$ & $\begin{array}{l}\text { Proinflammatory biomarker released } \\
\text { by lipoprotein-associated phospholipase } \\
\text { A2, variants } 16: 0 \text {, 18:0, I8:I }\end{array}$ & $\begin{array}{l}\text { Macrophages, vascular } \\
\text { endothelium }\end{array}$ \\
\hline Normal serum concentration & $<235 \mathrm{ng} / \mathrm{mL}$ & $\begin{array}{l}1.6-10 \mathrm{mg} / \mathrm{mL} \\
2: 1\end{array}$ & $<2.6 \mathrm{ng} / \mathrm{mL}$ \\
\hline Mean cutoff value & $>235 \mathrm{ng} / \mathrm{mL}$ & $>10 \mathrm{mg} / \mathrm{mL}$ & $27.75 \mathrm{ng} / \mathrm{mL}$ \\
\hline Predicts & $\begin{array}{l}\text { Atherosclerosis, ACS, } \\
\text { cardiovascular disease, ischemic } \\
\text { stroke }\end{array}$ & Atherosclerosis, cardiovascular disease & $\begin{array}{l}\text { Atherosclerosis, coronary } \\
\text { artery disease, heart failure; } \\
\text { associated with the number } \\
\text { of affected coronary vessels }\end{array}$ \\
\hline Clinical relevance & $\begin{array}{l}\text { Atherosclerosis, diagnostic } \\
\text { marker for CAD }\end{array}$ & $\begin{array}{l}\text { Prevention of cardiovascular disease, } \\
\text { diagnostic marker for CAD, prognostic } \\
\text { marker for CAD }\end{array}$ & $\begin{array}{l}\text { CAD, diagnostic marker } \\
\text { for CAD, predicting } \\
\text { severity of CAD }\end{array}$ \\
\hline $\begin{array}{l}\text { Statistical association } \\
\text { between biomarker and } \\
\text { myocardial infarction }\end{array}$ & $\mathrm{HR}=\mathrm{I} . \mathrm{II}, 95 \% \mathrm{Cl}=1.04-\mathrm{I} .18$ & & \\
\hline $\begin{array}{l}\text { Statistical association between } \\
\text { biomarker and angina } \\
\text { Statistical association between } \\
\text { biomarker and CAD }\end{array}$ & & & $P<0.001$ \\
\hline $\begin{array}{l}\text { Statistical association between } \\
\text { biomarker and death }\end{array}$ & $\mathrm{HR}=\mathrm{I} .0 \mathrm{I}, 95 \% \mathrm{Cl}=0.94-\mathrm{I} .09$ & & \\
\hline References & $70-73$ & 74 & 75 \\
\hline
\end{tabular}

Abbreviations: $\mathrm{ACS}$, acute coronary syndrome; $\mathrm{CAD}$, coronary artery disease; $\mathrm{HR}$, hazard ratio; $\mathrm{Cl}$, confidence interval.

and risk of coronary events. The role of Lp-PLA2 in atherosclerosis and cardiovascular risk still remains unclear.

\section{Lysophosphatidylcholine}

The level of lysophosphatidylcholine (lysoPC), a proinflammatory biomarker that is released in vitro but also in vivo by Lp-PLA2, was examined with respect to the severity of inflammation in atherosclerotic plaques by Gonçalves et al. ${ }^{74}$ Lp-PLA2 hydrolyzes LDL-oxidized phospholipids to produce lysoPC. Elevated plasma Lp-PLA2 was associated with higher cardiovascular risk and inhibition of Lp-PLA2 with a reduction in atherosclerosis. Inflammatory activity in carotid plaques from patients was studied immunohistochemically and by analysis of cytokines in homogenates using a multiplex immunoassay. Elevated levels of lysoPC and Lp-PLA2 correlated with high levels of plaque-associated macrophages and lipids and with a small smooth muscle cell component, while the level of lipophospatidic acid (LPA) was associated only with the number of plaque-associated macrophages. The relationships among Lp-PLA2, lysoPC, LPA, and proinflammatory cytokines in carotid plaques suggest that lysoPC is involved in plaque inflammation and vulnerability. These results validated inhibition of Lp-PLA2 as a promising approach to the prevention of cardiovascular disease (Table 4).

\section{Galectin-3}

Galectin-3 is a mediator of infection and inflammation controlled by macrophages and the vascular endothelium. As galectin-3 mediates the inflammatory process, it may be linked to the development of the atherosclerosis component of coronary artery disease. Remarkably, patients with three-vessel coronary artery disease had higher serum concentrations of galectin-3 than those with one- or two-vessel coronary artery disease. The significantly elevated serum levels of galectin-3 observed in patients with UA in this study support the role of galectin-3 in supporting macrophage stimulation and monocyte activity. The similar incidence rates of coronary artery disease in patients with acute and chronic coronary artery disease can be disregarded. ${ }^{75}$

\section{Proinflammatory cytokine markers: interleukins}

\section{Interleukin-6}

Interleukin (IL)-6 is a key mediator of the inflammatory process. It is also associated with rheumatoid arthritis and its activity may be controlled by the IL-6 receptor (IL-6R). The effects of the IL-6R and IL-6ST/gp130 genes on the risk for cardiovascular disease in patients with rheumatoid arthritis were assessed in patients with rheumatoid arthritis 
who were genotyped for the functional gene polymorphisms. In summary, no association was evident between the polymorphisms of IL genes and cardiovascular disease in subjects with rheumatoid arthritis. ${ }^{76}$

Coronary plaque rupture is linked with a systemic inflammatory response. Van Diepen et $\mathrm{al}^{77}$ studied the relationships between the baseline level of NT-proBNP and the baseline levels of biomarkers of inflammation and myonecrosis. In patients with STEMI treated by primary PCI, the baseline level of NT-proBNP was slightly associated with the level of the proinflammatory cytokine IL-6. This association remained significant in patients without heart failure. These findings confirmed the hypothesis that systemic inflammation may influence NT-proBNP expression independently of myocardial stretch.

Fan et $\mathrm{al}^{78}$ conducted a prospective cohort study of patients with STEMI in which they recorded all clinical data as well as the serum levels upon admission of IL-6, soluble intercellular adhesion molecule-1, soluble vascular cell adhesion molecule-1, and soluble P-selectin. This study showed that high levels of IL-6 could predict mortality due to MI, but that soluble adhesion molecules do not predict cardiovascular mortality.

\section{Interleukin-10}

IL-10 is an immunoregulatory cytokine. This small cellsignaling protein is produced by a variety of cell types, such as macrophages and activated monocytes. These signaling molecules regulate many anti-inflammatory, antithrombotic, and antiatherosclerotic processes. In addition, patients with ACS have been shown to have lower levels of IL-10 than those with stable angina pectoris. Therefore, many researchers have suggested that IL-10 protects against both atherogenesis and plaque vulnerability. Two different studies have examined the predictive value of the IL-10 level in patients with ACS, with discordant results: one study found that low levels of IL-10 predicted different outcomes, and another showed that elevated levels predicted poor outcomes. ${ }^{79,80}$ The prospective study by Cavusoglu et $\mathrm{al}^{79}$ aimed to explore the long-term predictive value of the baseline IL-10 level in patients with ACS. These results clearly show that regardless of the biologic plausibility of any cardioprotective function for IL-10, a high baseline plasma level of IL-10 is a strong and independent predictor of long-term adverse cardiovascular events in patients with ACS.

The circulating level of IL-10 demonstrated few strong associations with classical risk factors, but correlated positively with the levels of IL-6 and CRP. After adjustment for classical risk factors and the level of CRP, the IL-10 level remained positively associated with the risk for cardiovascular disease events. Furthermore, IL-10 was more strongly associated with risk for cardiovascular disease in subjects with no previous history of cardiovascular disease than in subjects with a prior history of cardiovascular disease. Overall, IL-10 showed a modest superiority over classical risk factors. The baseline circulating level of IL-10 was positively associated with the risk for developing cardiovascular disease in elderly subjects without prior history of cardiovascular disease, but this association was less evident in subjects with a history of cardiovascular disease. Additional epidemiological and mechanistic studies to investigate the role of IL-10 in the development of cardiovascular disease are warranted..$^{80}$

\section{Interleukin- |3, interleukin- I7, and interleukin- I8}

As described earlier, cytokines play important roles in the pathogenesis of cardiovascular diseases. A previous published study analyzed the plasma levels of IL-13, IL-17, and IL-18 in patients with coronary artery disease and explored their relationships with established risk factors. The frequency of participants with detectable levels of IL-13 was significantly higher in the control group than in the STEMI group or in the total population of patients with coronary artery disease. The mean plasma levels of IL-17 were significantly higher in the STEMI and UA groups than in the control group. In addition, the mean plasma level of IL-18 was significantly higher in the UA group than in the control group. The mean plasma level of IL-18 was higher in the total population of coronary artery disease patients without a common risk factor, as well as in the subgroups without hypertension, dyslipidemia, diabetes, or a history of smoking than in the control group. These outcomes revealed that elevated plasma levels of IL-17 and IL-18 were related to coronary artery disease. The presence or absence of various established risk factors for coronary artery disease could influence the plasma levels of these cytokines. ${ }^{81}$ These discoveries might enhance the predictive values of inflammatory cytokines for coronary artery disease and also help in the development of new therapeutic strategies.

\section{Interleukin-27}

A previously published study aimed to examine the plasma level of IL-27 in patients with coronary artery disease to determine its association with common risk factors for coronary artery disease. The mean plasma level of IL-27 was significantly higher in the AMI and UA groups than in the control 
group. The mean plasma level of IL-27 was significantly higher in patients with coronary artery disease, with or without common risk factors such as hypertension, dyslipidemia, diabetes, and a history of smoking, than in the control group. These findings showed that elevation of the plasma level of IL-27 is related to coronary artery disease. The presence or absence of certain traditional risk factors for coronary artery disease did not influence the serum level of this cytokine. ${ }^{82}$

\section{Soluble ST2 and interleukin-33}

Soluble ST2 is a biomarker of biomechanical loading; IL-33 is a natural ligand for ST2. These potential biomarkers for coronary artery disease have been analyzed in patients with NSTEMI. Their relationships with major adverse cardiac events (MACE), both combined and separately, were examined in unselected patients using the Global Registry of Acute Coronary Events (GRACE) Risk Scoring score and the level of NT-proBNP as benchmarks for comparison. The ST2 level was higher in patients who experienced MACE than in event-free survivors, while the IL-33 level did not differ significantly between these groups as of the end of the study. Multivariate Cox regression analysis showed an elevated level of ST2 to be independently associated with higher long-term risk for MACE. This relationship persisted after adjustment for either the GRACE risk score or the NT-proBNP level individually, but not after adjustment for both benchmarks. The ST2 level also predicted recurrent infarction and 30-day mortality individually. Moreover, combining the ST2 level with the GRACE score or NT-proBNP level did not significantly change the c-statistic for MACE for long-term follow-up or the net reclassification index. Neither the IL-33 level nor the IL-33:ST2 ratio was related to the study endpoints. An elevated level of ST2 predicts unfavorable outcomes in patients with NSTEMI, but does not significantly change the risk stratification by accepted biomarkers. In addition, the level of IL-33 was not associated with adverse events. ${ }^{83}$

IL-33, a cytokine in the IL-1 family, was neglected in medical science until recently. Unlike other cytokines such as IL- $1 \alpha$, IL-1 $\beta$, and IL-18, IL-33 stimulates mainly T helper type 2 (Th2)-skewed immune responses, meaning that its activity is generally anti-inflammatory. Nevertheless, depending on the existing cytokine and cellular milieu, IL-33 can support both Th1 and Th2 immune responses. IL-33 is considered important mainly for cardiology and surgery, and appears to be the formerly unidentified ligand of the orphan receptor ST2. ${ }^{84}$ Before it was linked to IL-33, the ST2 sensory receptor (the membrane-bound isoform, which has been ignored in favor of the soluble isoform) was regarded to be unusable for predicting MI or heart failure, or for identifying patients with trauma or septic shock. ${ }^{84}$ The authors now acknowledge that IL-33, when bound to the cellular membrane-anchored ST2 L isoform of ST2, can have several beneficial effects as described above.

\section{Interleukin- 18}

Another study aimed to survey the plasma level of IL-18 in patients with coronary artery disease and type 2 diabetes mellitus, and to associate it with the clinical findings. The control group consisted of age-, BMI-, lipid-, and smoking status-matched healthy individuals. Age, BMI, grade of heart failure, and ejection fraction were similar between patients with coronary artery disease with and without diabetes. The duration of coronary artery disease, frequency of history of previous MI, and PCI or instability of angina did not differ between the groups. The plasma level of IL-18 was higher in the patients with coronary artery disease than in the control group. The patients with coronary artery disease and diabetes mellitus had higher concentrations of IL-18 than those with coronary artery disease without diabetes. The patients with diabetes with triple-vessel coronary artery disease exhibited higher levels of IL-18 than those with the same level of coronary artery disease but without diabetes. In addition, smoking was associated with a higher concentration of IL-18, especially in the patients with diabetes. Patients with threevessel coronary artery disease who were smokers had higher serum levels of IL-18, which accounts for their vulnerability to death and unexpected recurrent MI. These patients should be managed more strictly for the prevention of cardiovascular disease. ${ }^{85}$

\section{Interleukin-I receptor antagonist}

IL-1 receptor antagonist (IL-1Ra) levels are elevated before the onset of disease in patients with STEMI and often promote liberation of the markers of necrosis. Nonetheless, IL-1Ra levels are not related to infarct size or medical prognosis in such patients. The relationships between the IL-1Ra levels measured in the emergency department, as well as the degree of myocardial necrosis and prognosis in patients with STEMI, were evaluated prospectively. The maximal levels of creatine kinase (CK) and CK-MB measured during hospitalization were recorded, and the LVEF was examined by electrocardiography before discharge from the hospital. The concentration of IL-1Ra measured in the emergency department correlated directly with the maximal levels of CK and CK-MB and inversely with the LVEF before discharge. The IL-1Ra concentration measured in 
the emergency department was significantly higher in patients who experienced unexpected outcomes in hospital than in those who did not. In patients with STEMI, the concentration of IL-1Ra measured in the emergency department correlated significantly with the level of myocardial necrosis, as indicated by the peak levels of cardiac enzymes, and with a reduction in LVEF; this was predictive of in-hospital events. ${ }^{86}$ The results of this study suggest that IL-1Ra antagonism is a potential therapeutic approach to STEMI.

\section{Transforming growth factor $\beta$ receptor I}

Left ventricular remodeling after STEMI is very important for heart function; therefore, a biomarker for left ventricular remodeling could help to determine the prognosis for ventricular function. A search for new biomarkers that included transforming growth factor beta (TGF- $\beta$ ) receptor 1 as a candidate was performed in patients with STEMI who underwent PCI. ${ }^{87}$ This study identified TGF- $\beta$ receptor 1 as a new predictive biomarker for left ventricular function after STEMI.

\section{Development of a biomarker profile for risk assessment}

This section addresses clinical studies that have demonstrated the superior diagnostic and risk-assessment triage sensitivity of combinations of inflammatory biomarkers. Interestingly, these studies identified different panels of markers as better for predicting the first ischemic episode and the risk of multiple episodes. Furthermore, some markers that exhibit poor diagnostic power when used alone may be more relevant as part of a panel of biomarkers.

A panel of seven biomarkers that had individually been shown to be independent predictors of coronary artery disease was evaluated for the prediction of long-term cardiovascular outcome after ACS. The levels of hs-CRP, MPO, PAPP-A, PIGF, sCD40L, IL-10, and TnT were determined in patients with ACS who were enrolled in the Chimeric Anti-Platelet Therapy in UA Refractory to standard medical therapy (CAPTURE) trial. It was found that the use of combinations of selected biomarkers adds incremental predictive value to alternative risk stratification methodologies in an otherwise seemingly homogeneous population of patients with $\mathrm{ACS} .{ }^{88}$

\section{Interleukin-6, interleukin-I, tumor} necrosis factor- $\alpha$ (TNF- $\alpha$ ), interleukin- 10 A different study by Dizdarević-Hudić et $\mathrm{al}^{89}$ investigated the relationships among the proinflammatory cytokines IL-6,
IL-1, and tumor necrosis factor (TNF)- $\alpha$, as well as the antiinflammatory cytokine IL-10 in patients with AMI and stable angina pectoris; the relationship between IL-6 and IL-10 in patients with AMI and stable angina pectoris; and the association between IL-6 and lipoproteins in patients with AMI. The IL-6:IL-10 ratio was significantly higher in patients with AMI than in those with stable angina. The TNF- $\alpha$ :IL-10 ratio was also higher in the study group, but this difference was not significant. The authors also found a positive linear correlation between the levels of IL- 6 and IL-10 and a negative linear correlation between the levels of IL- 6 and high-density lipoprotein in patients with AMI. The IL-6:IL-10 ratio was higher in patients with AMI than in those with stable angina. The level of IL- 6 correlated linearly with those of IL-10 and high density lipoprotein (HDL) in patients with AMI.

\section{Interleukin- 10 and single nucleotide polymorphism (SNP)}

The plasma level of IL-10 and the frequency of a single nucleotide polymorphism (SNP) were analyzed in conjunction with the rates of death and MI within 12 months in a different prospective study of patients with ACS and healthy subjects. Seven tag SNPs within and flanking the $I L-10$ gene were selected from the Seattle SNP database. The $1170 \mathrm{C}>\mathrm{T}$ SNP was in complete allelic association with several other variants in the $I L-10$ gene, including the SNPs $-592 \mathrm{C}>\mathrm{A}$ and $-819 \mathrm{C}>\mathrm{T}$, and was selected to tag these genetic variants. The A allele of $-592 \mathrm{C}>\mathrm{A}$ and the $\mathrm{T}$ allele of -819 $\mathrm{C}>\mathrm{T}$ have previously been linked to a lower expression IL-10 messenger ribonucleic acid. In patients, the IL-10 level predicted much higher risk for death and MI, with the greatest effect observed in the fourth quartile. Correction for general risk indicators such as the levels of CRP and IL- 6 destabilized the association to a nonsignificant degree..$^{90}$ These results differed from those of some earlier studies. ${ }^{90}$ The authors concluded that IL-10 is important to the proinflammatory state in patients with ACS and proposed that IL-10 and other markers of systemic inflammation may therefore be helpful as biomarkers of the risk for cardiovascular events.

\section{The proinflammatory HLA-DRB I*0I - haplotype}

The major histocompatibility complex (MHC) gene region is associated with coronary artery disease. This relationship was further investigated in patients with STEMI. Four histocompatibility markers were examined by polymerase chain reaction in patients with STEMI, a matched control group of patients without coronary artery disease, and a general 
sample of healthy individuals. A continuous study of patients that included other study participants investigated the level of hs-CRP. The haplotype with a copy of HLA-DRB $1 * 01$, $\mathrm{C} 4 \mathrm{~A}$, or $\mathrm{C} 4 \mathrm{~B}$, but not HLA-B*35, was associated with a twofold-higher risk for STEMI. The frequency of the highrisk haplotype was $5.86 \%$ in the patients with STEMI, $2.82 \%$ in the control subjects, and $2.68 \%$ in the population sample. None of the individual MHC markers alone was significantly associated with STEMI. After multivariate analysis, the hs-CRP level was significantly higher among the haplotype carriers in both the patient and control groups. The MHC haplotype correlated with both the presence of STEMI and an elevated baseline level of hs-CRP. The results agreed with previous data from patients without STEMI that the HLADRB $1 * 01$-related haplotypes increased the risk for coronary artery disease, possibly through increased inflammation. ${ }^{91}$

\section{Endothelial progenitor cells (EPC), stromal cell-derived factor (SDF)- $\mid \alpha$, and IL- IO}

The associations of the circulating levels of endothelial progenitor cells (EPC), stromal cell-derived factor (SDF)-1 $\alpha$, and IL-10 with outcomes were investigated in patients with STEMI treated by primary coronary angioplasty. The IL-10 level was higher and the circulating level of EPC (E[1-2]) was lower in patients with STEMI than in healthy subjects. An elevated SDF-1 $\alpha$ level was significantly and independently associated with an elevated level of circulating EPC (E[1-2]). In addition, patients with an elevated level of SDF-1 $\alpha$ had worse left ventricular function, a greater frequency of high Killip scores, and greater 30-day mortality than those with low SDF-1 $\alpha$ levels. Furthermore, elevated circulating levels of E(2) and IL-10 were the most significant independent predictors of 30-day major adverse clinical outcomes. These results indicate that the serum SDF-1 $\alpha$ level is independently associated with the level of circulating EPC (E[1-2]). E(2) and IL-10 are major independent predictors of 30-day major adverse clinical outcomes in patients with STEMI treated by PCI. ${ }^{92}$

\section{Growth differentiation factor 15}

Growth differentiation factor 15 (GDF-15), a stressresponsive member of the TGF- $\beta$ cytokine superfamily, has been investigated as a biomarker for increased mortality from cardiovascular disease. However, the precise pathophysiological roles of GDF-15 in the cardiovascular system and in acute STEMI are not well defined. In summary, the GDF-15 concentration at admission strongly predicts mortality in patients with STEMI reperfused by PCI and is associated with lower myocardial salvage and subsequent adverse clinical outcomes. ${ }^{93}$

\section{GDF-I5, hs-cTnT, and NT-proBNP}

A prospective, international, multicenter study analyzed the levels of GDF-15, hs-cTnT, and NT-proBNP, and the mortality in patients with UA. The level of GDF-15 upon admission was markedly higher in patients with AMI than in those with other diagnoses. Moreover, the level of GDF-15 predicted MI more precisely than that of hs-cTnT. Therefore, the level of GDF-15 predicted all deaths in a nonselected population of patients with UA independently of and more accurately than those of hs-cTnT and NT-proBNP. However, the GDF-15 level does not appear to assist in the primary diagnosis of AMI. ${ }^{94}$

\section{hs-CRP and NT-proBNP}

Stable coronary artery disease carries a poor prognosis. In the recently published CLARICOR (effect of clarithromycin on mortality and morbidity in patients with ischemic heart disease) trial, investigators evaluated the extent to which the hs-CRP and NT-proBNP measurements, alone or in combination, could function as prognostic biomarkers in patients with stable coronary artery disease. In summary, the hs-CRP had no additive value over the NT-proBNP level for predicting the prognosis in patients with stable coronary artery disease. ${ }^{95}$

\section{Prepro-A-type natriuretic peptide}

New biomarkers could be useful for clinical decision making in patients with cardiovascular disease. A previous study developed a new immunoassay for the signal peptide of prepro-A-type natriuretic peptide (ANPsp) and used it to measure the concentration of ANPsp in human cardiac tissue, the venous blood concentration of ANPsp in healthy volunteers, the change in the ANPsp concentration over time in patients with STEMI, and the regional ANPsp plasma level in patients in whom catheterization was clinically indicated. ${ }^{96}$ In patients with STEMI, the plasma concentration of ANPsp increased to its maximal level about 5 hours after the onset of symptoms, much earlier than the levels of myoglobin, CK-MB, or troponin. The arteriovenous ANPsp concentrations in the heart and kidneys did not increase significantly, and both the arterial and coronary sinus concentrations of ANPsp correlated negatively with systolic and mean arterial blood pressure. A tandem mass spectrometry differentiated the different subgroups of preproANP. ANPsp is a novel circulating natriuretic peptide that could be used as a biomarker for coronary artery disease. ${ }^{96}$ The rapid increase in 
serum ANPsp with increasing blood pressure in patients with STEMI strongly warrants further investigation.

\section{Biomarker combinations including ischemia-modified albumin C-reactive protein and albumin-to- creatinine ratio}

CRP is an established prognostic marker in patients with ACS. Recently, an elevated albumin excretion rate has also been associated with adverse outcomes in such patients. ${ }^{97}$ The predictive values of the CRP level and the albumin excretion rate for long-term mortality following STEMI were compared among patients with STEMI and heart failure. All patients were followed up after 10 years, and survival analysis showed that elevation of either the CRP level or the albumin-to-creatinine ratio was associated with greater risk for 10-year all-cause mortality even after adjustment for age, hypertension, diabetes mellitus, prehospital time delay, CK-MB isoenzyme peak, heart failure, and creatinine clearance. Both the CRP level and the albumin-to-creatinine ratio were associated with nonsudden cardiovascular mortality, but not with sudden death or nonsudden cardiovascular death. While an elevated CRP level was not associated with long-term mortality, an elevated albumin-to-creatinine ratio was independently associated with a negative cardiovascular outcome in both the short- and long-term analyses. C-statistic analysis showed that the addition of the CRP level improved the baseline prediction model for short-term nonsudden cardiovascular mortality, but not that for all-cause mortality. In contrast, the addition of the albumin-to-creatinine ratio improved the short- and long-term prediction of all-cause and nonsudden cardiovascular mortality. Moreover, the albumin-to-creatinine ratio was superior to the CRP level for predicting long-term mortality after the development of STEMI. ${ }^{97}$

\section{Ischemia-modified albumin}

Recent studies have shown ischemia-modified albumin (IMA) to be a new marker of AMI. This relationship was further examined in patients with UA. The serum level of IMA was compared between patients with and without coronary artery disease. Notably, the mean serum level of IMA did not differ significantly between patients with and without coronary artery disease. The plasma level of IMA did not predict the deaths. Therefore, this study found the IMA level to be unsuitable for evaluating AMI. ${ }^{98}$

However, despite the findings of the abovementioned study, the United States Food and Drug Administration lists
IMA as a biomarker of MI. Therefore, the utility of IMA as a biomarker for heart attack was further investigated in a study of patients admitted with ACS. The serum levels of aspartate aminotransferase, isoenzyme of CK activity, TnT, NT-proBNP, CRP, and IMA, as well as the creatinine clearance were measured in all patients. In addition, all patients underwent coronary angiography after admission to the hospital. The proportion of patients with an elevated serum level of IMA did not differ significantly between the groups. Notably, the plasma level of IMA could not differentiate between ACS and NSTEMI in this study, and an elevated serum level of IMA was significantly associated only with the duration of ACS. ${ }^{99}$

\section{CK, CK-MB, enhanced AccuTnl, hs-cTnT, IMA, IL-6, high-sensitivity cardiac troponin I, NT-proBNP, and cardiac troponin I}

Another study examined the usefulness of nine markers for the early diagnosis of MI. The levels of the biomarkers CK, CK-MB, enhanced AccuTnI (Beckman Coulter, Inc, Brea, CA, USA), hs-cTnT, IMA, IL-6, high-sensitivity cardiac TnI, NT-proBNP, and cardiac TnI were analyzed in patients with ACS. The following outcomes were recorded for all patients: heart failure, dangerous arrhythmia, refractory ischemic cardiac pain, and death. Furthermore, receiver operating characteristic curves were plotted to determine the area under the curve and optimum cut-off level for each biomarker. The area under the curve values were significantly higher for the high-sensitivity cardiac TnI test, the AccuTnI assay, and the hs-cTnT test than for the other six tests. The ideal cutoffs for predicting serious cardiac outcomes in this high-risk population differed from the published 99th percentiles. ${ }^{100}$ Therefore, larger studies are needed to confirm the findings of this investigation.

\section{Haptoglobulin}

The use of haptoglobulin as biomarkers for the early detection of MI was studied by Haas et al. ${ }^{101}$ The plasma levels of albumin and immunoglobulin $\mathrm{G}$ were measured by twodimensional fluorescence difference gel electrophoresis, and the degree of heart failure according to the New York Heart Association (NYHA) classification was determined 1 year later in these patients. After the main part of the analysis, ranked clustering of proteomics data revealed that the patients could be divided into three groups. The 22 differentially distributed proteins that determined this grouping included haptoglobin (Hp), which has several isoforms. The three groups of patients had clearly distinct Hp genotypes: patients 
in group 1 had the $\alpha 1-\alpha 1$, patients in group 2 the $\alpha 2-\alpha 1$, and patients in group 3 had the $\alpha 2-\alpha 2$ genotype. This categorization was also related to variations in the total plasma level of Hp. Both the presence of the $\alpha 2$ genotype and a low plasma level of Hp were associated with a higher NYHA class and therefore with greater functional injury after MI. A serum level of $\mathrm{Hp}<1.4 \mathrm{~g} / \mathrm{L}$ forecast the detection of heart failure (NYHA 2, 3, or 4) 1 year later with 100\% sensitivity.

\section{Heart fatty acid-binding protein and IMA}

A recently published study evaluated the biomarkers H-FABP and IMA for the early detection of MI. ${ }^{102}$ This study examined the diagnostic accuracy and clinical usefulness of the H-FABP and IMA levels in patients who presented with signs consistent with ACS. While the IMA level could not effectively identify the patients with ACS, the H-FABP level predicted the ACS diagnosis with 13.5\% sensitivity and $96.8 \%$ specificity. However, the biomarker H-FABP did not help to identify patients with NSTEMI. Therefore, the biomarkers IMA and H-FABP did not supply important information for the evaluation of patients with possible ACS. ${ }^{102}$

\section{IMA, cTnl, and CRP}

Various studies have proposed IMA to be a novel and sensitive biochemical biomarker for the early detection of MI. The authors measured the levels of IMA, cardiac TnI, and CRP in all patients within 3 hours of the last symptom of ACS. They also recorded the occurrence of MACE, including cardiac death, nonfatal MI, and recurrent coronary ischemia. The independent predictive value of the level of IMA was evaluated using a logistic regression model and compared consistently with those of established clinical markers and biomarkers. The mean level of IMA was significantly higher in patients who experienced MACE either during hospitalization or within 1 year than in patients who remained MACE-free. After adjustment for traditional risk factors, the IMA level was an independent predictor of MACE both during hospitalization and at one year. In addition, the initial level of IMA was associated with the short-and long-term occurrence of cardiovascular events in patients with NSTEMI and ACS. ${ }^{103}$

\section{Albumin, CRP,Tnl, and alpha I- microglobulin}

Microalbuminuria has been associated with MI in several studies. ${ }^{104}$ In order to clarify this connection, Holm et al ${ }^{104}$ examined whether dysfunctional tubular reabsorption of filtered albumin leads to microalbuminuria during MI, and whether the urinary elimination of protein is associated with the plasma levels of CRP and TnI. The serum levels of CRP and TnI, and also the urinary elimination of albumin and alpha1-microglobulin - a low-molecular-weight plasma protein and biomarker of tubular proteinuria - were measured in patients with MI. The urinary elimination of alpha1-microglobulin and albumin was significantly elevated in nine patients, and the rates of urinary secretion of the two proteins correlated significantly. Reduced tubular reabsorption of albumin may be at least one of the causes of microalbuminuria during MI. The serum levels of CRP and TnI were also significantly elevated in these nine patients. This correlation between the levels of inflammatory biomarkers and urinary protein elimination suggests a relationship between the inflammatory process and tubular dysfunction. In summary, extrarenal inflammatory processes appear to impair kidney function during MI.

\section{Categories of inflammatory biomarkers Procalcitonin}

The clinical consequences of elevated procalcitonin (PCT) levels for the development of ACS were investigated in patients with ACS. The mean PCT level within 48 hours of hospital admission was significantly higher in the five patients who died during hospitalization than in the survivors. Furthermore, the mean PCT level within 48 hours after admission was significantly higher in the nine patients who died within 6 months than in the long-term survivors. Higher PCT levels within 48 hours after admission were concluded to indicate an inflammatory process associated with increased early and 6-month mortality rates. ${ }^{105}$

Bektas et a $1^{106}$ evaluated PCT as a possible biomarker for the early detection of MI. The PCT level predicted MI in patients with ACS with $38.3 \%$ sensitivity and $77.8 \%$ specificity. In summary, PCT was a poor predictor of MI.

The relationships between the PCT level and outcome measures such as MACE, left ventricular function, and myocardial healing after STEMI were evaluated in another study by Kelly et al. ${ }^{107}$ The PCT level was also associated with biomarkers of left ventricular dysfunction and myocardial healing. In summary, PCT was associated with MACE, left ventricular dysfunction, and myocardial recovery after STEMI. The authors of this article proposed PCT to be a potentially useful prognostic biomarker for the early identification of STEMI. ${ }^{108}$

Quite different was the study by Schiopu et al. ${ }^{109}$ Namely, PCT was investigated for the prediction of cardiovascular events in healthy subjects. This study found significant 
associations between PCT, coronary events, cardiovascular death, and cardiovascular risk factors in healthy individuals without previous coronary artery disease. Nevertheless, these relations between PCT and cardiovascular risk in healthy individuals became less significant when the analysis was considered with the CRP and traditional risk factors for cardiovascular events such as hypertension, diabetes, and renal function. Therefore, PCT has a limited value for predicting cardiovascular events in healthy subjects.

\section{Soluble CXC chemokine ligand 16}

Coronary stenoses in high-risk patients cannot be identified as early as would be desirable. The former discovered inflammatory mediator, soluble CXC chemokine ligand 16, which is liberated by proteolytic cleavage of its membrane-bound form scavenger receptor for phosphatidylserine and oxidized lipoprotein - which promotes the uptake of oxidized LDL cholesterol by macrophages - has been studied as an indicator of the average prognosis for lesions in coronary vessels. In summary, the plasma level of the soluble CXC chemokine ligand 16 was an independent predictor of the prognosis in patients at greater risk for cardiovascular events. ${ }^{110}$

\section{Proteinase 3}

Risk could be assessed in patients with STEMI using multimarker systems related to multiple pathophysiological pathways. The prognostic value after STEMI of the putative inflammatory marker proteinase 3 (PR3) has been compared with that of the established marker NT-proBNP. In conclusion, this was the first study to show a possible role for serine protease PR3 in predicting mortality and heart failure after STEMI, independently of the established conventional risk factors. ${ }^{111}$ PR 3 could be clinically useful as part of a multimarker strategy for determining the prognosis after STEMI.

\section{C3:C4 concentration ratio}

ACS is an inflammatory disease involving activation of the complement system. The ratio of the serum concentrations of the complement components $\mathrm{C} 3$ and $\mathrm{C} 4(\mathrm{C} 3: \mathrm{C} 4$ ratio) was analyzed as a potential indicator of prognosis after MI. ${ }^{112}$ Patients with ACS were followed after a heart attack. The endpoints were death, MI, recurrent UA, and stroke. The $\mathrm{C} 3$ :C4 ratio was higher in patients who met an endpoint during the follow-up period than in those who did not. A Cox multivariate logistic regression model including all of the traditional cardiovascular risk factors and other potential confounders showed the $\mathrm{C} 3: \mathrm{C} 4$ ratio to be a novel risk factor for any new cardiovascular event. In summary, the serum $\mathrm{C} 3: \mathrm{C} 4$ ratio is a readily available novel marker for recurrent cardiovascular events in patients with ACS. Either a relative increase in the serum concentration of $\mathrm{C} 3$ or a decrease in the concentration of $\mathrm{C} 4$ may account for such changes in the $\mathrm{C} 3: \mathrm{C} 4$ ratio. $^{112}$

\section{Soluble intercellular adhesion molecule I}

The most recently debated marker for coronary artery disease is the circulating form of membrane-engaged intercellular adhesion molecule 1. Elevated intercellular adhesion molecule 1 levels have also been observed in patients with other cardiovascular diseases, including myocarditis, inflammatory cardiomyopathy, and cardiac insufficiency. ${ }^{113}$

\section{Discussion}

The importance of inflammatory biomarkers in both diagnosing and determining the prognosis for coronary artery disease is now well established. Furthermore, several newer biomarkers have recently been identified and may soon be applied clinically. The emergence of different biomarkers of coronary artery disease provides insight into the varied pathophysiology of this disease.

PTX3 appears to be more specific than CRP to the development of vascular inflammation. Higher concentrations of PTX3 have been associated with increased risk for cardiovascular events. Additional studies of the association of PTX3 with coronary artery disease are required to clarify both of these properties.

Biomarkers of plaque instability are not appropriate for the diagnosis of coronary artery disease, although they may be useful for stratification of the risk for MI. However, multimarker testing could reveal that these biomarkers are complementary to one another for the detection of coronary artery disease. The future of coronary artery disease work-up could thus shift from single-marker to multimarker testing.

The relationship between the circulating level of Lp-PLA2 and coronary plaque volume was investigated in patients with ACS in a study conducted by Dohi et al. ${ }^{70}$ This study was limited by its small sample size, so further prospective studies examining a larger patient population are required to clarify the association between Lp-PLA2 and arteriosclerosis in patients with coronary artery disease. In addition, according to Garg et al, ${ }^{71}$ Lp-PLA2 is not associated with the endothelial dysfunction observed during the development of atherosclerosis. Rather, other factors appear to be more important to the mechanism of atherosclerosis. The IL-6 level is not associated with either coronary artery disease or rheumatoid 
arthritis according to López-Mejías et al. ${ }^{76}$ The level of IL-6 also did not differ between patients who did and did not experience cardiovascular events in that study.

According to Welsh et al, ${ }^{80}$ low baseline circulating levels of IL-10 are positively associated with risk for developing cardiovascular disease despite the weak association between the IL-10 level and a history of cardiovascular events.

A combination of the neutrophil count and TnT level did not contribute to the early diagnosis of AMI in the prospective observational study performed by Meissner et al, ${ }^{57}$ although patients with AMI and a high neutrophil count were at increased risk for cardiovascular-related mortality. An elevated neutrophil count may be related to coronary artery disease.

A high level of the TGF- $\beta$ superfamily member GDF-15 is a strong predictor of mortality in patients with STEMI. Future studies should investigate the significance of this biomarker in patients with ACS, stable angina pectoris, and acute coronary artery disease.

Harutyunyan et $\mathrm{a}^{95}$ found that analysis of the level of hs-CRP did not improve the prediction of coronary artery disease, although the level of hs-CRP alone or in combination with that of NT-proBNP could function as a prognostic biomarker in patients with stable coronary artery disease. Additionally, Berton et a ${ }^{97}$ reported that the combination of $\mathrm{CRP}$ and the albumin-to-creatinine ratio predicts long-term mortality after AMI better than CRP alone. This relationship between these parameters requires further investigation in cases of acute coronary artery disease that occur after coronary angiography.

Further research is required to confirm whether the inflammatory marker, PCT, is useful for the early diagnosis of atherosclerosis in patients with ACS.

The extent of a MI could be predicted from the circulating levels of homocysteine and TnI. The serum homocysteine level was positively associated with the severity of coronary injury. The plasma level of homocysteine could also predict the extent to which heart failure worsened after MI.

The erythrocyte sedimentation rate has $67.65 \%$ sensitivity and $70.59 \%$ specificity for coronary artery disease and could potentially provide additional diagnostic value in patients with coronary artery disease. The erythrocyte sedimentation rate showed no association or interaction with the blood glucose level or the inflammatory response.

A previously published study discovered an association of a high level of classical monocytes with severe myocardial injury and poor functional outcome after STEMI. ${ }^{49}$ Future studies are needed to analyze the biological nature of this relationship.
Additional studies are also necessary to clarify the role of the CD40/CD40L system in the pathogenesis of coronary artery disease. An elevated level of CD40L was not associated with a significant increase in the risk for expected events in patients with ACS, and CD40L is not a useful biomarker for stroke or MI.

Amyloid A was a better marker than CRP for diagnosing coronary artery disease in patients with NSTEMI. The plasma amyloid A level may have been linked with left ventricular systolic dysfunction and poor patient outcomes (including mortality). Elevated levels of amyloid A and hs-CRP can be associated with the development of atherosclerosis.

Some studies have suggested fibrinogen to be involved in cardiovascular diseases. ${ }^{43-45}$ Fibrinogen is, in fact, a biomarker for coronary artery disease, and estimation of the fibrinogen level during MI could help to identify patients at high risk for an adverse event.

Infection or inflammation often increases the leukocyte count. Increased numbers of leukocytes, especially neutrophils, were independently associated with coronary artery disease. A leukocyte count above the reference range increased the risk for an ischemic event. ${ }^{53-56}$

The associations between Lp-PLA2, lysoPC, LPA, and proinflammatory cytokines in carotid plaques suggest that lysoPC is involved in plaque inflammation and vulnerability. On the basis of these findings, Gonçalves et al ${ }^{74}$ proposed Lp-PLA2 inhibition as a possible way to prevent cardiovascular disease.

The serum level of sLOX-1 detected the first stages of STEMI more precisely than the levels of H-FABP, myoglobin, TnT, and CK-MB according to Kobayashi et al. ${ }^{68}$ A case report also showed that measurement of the sLOX-1 level upon admission to the hospital to be helpful for diagnosing coronary artery disease in patients suspected of suffering MI.

The elevated serum level of galectin-3 found in patients with UA versus those with stable angina pectoris supports the activation of macrophages and monocytes by galectin-3 . Although the numerical distribution of coronary artery disease is about the same between patients with stable and UA pectoris, the results of this study suggest that galectin-3 may be a useful marker for coronary artery disease.

TGF- $\beta$ receptor 1 has been shown to be a novel indicator of the prognosis after AMI. ${ }^{87}$

GDF-15 may be a useful new marker for predicting death and heart failure in patients with STEMI. The level of GDF-15 provides predictive value over and above that of the established biomarker, NT-proBNP, or clinical parameters. 
The combination of GDF-15 and NT-proBNP could help to identify patients at high risk for MI.

Several studies have shown various ILs to be important in the pathogenesis of coronary artery disease. ${ }^{76-86}$

\section{Conclusion}

This review shows an overview of data with the complex relationship between cardiovascular disease and inflammatory biomarkers. A good independent marker for predicting cardiovascular disease seems to be PTX3, as it has more specificity than CRP. Markers with higher predictive power in combination were biomarkers of plaque instability for stratification of the risk for MI. The best risk assessment profile defined so far was the erythrocyte sedimentation rate, with high sensitivity and specificity for predicting coronary artery disease as additional diagnostic value. In addition, the IL family was a marker that was useful only as part of a panel. Single inflammatory markers have low predictive power for coronary artery disease; therefore, combinations of biomarkers were examined as predictors of coronary artery disease.

\section{Disclosure}

The author reports no conflicts of interest in this work.

\section{References}

1. Morrow DA, Sabatine MS, Brennan ML, et al. Concurrent evaluation of novel cardiac biomarkers in acute coronary syndrome: myeloperoxidase and soluble CD40 ligand and the risk of recurrent ischaemic events in TACTICS-TIMI 18. Eur Heart J. 2008;29(9):1096-1102.

2. Nagesh CM, Roy A. Role of biomarkers in risk stratification of acute coronary syndrome. Indian J Med Res. 2010;132:627-633.

3. Kumar A, Cannon CP. Acute coronary syndromes: diagnosis and management, part I. Mayo Clin Proc. 2009;84(10):917-938.

4. James SK, Armstrong P, Barnathan E, et al; GUSTO-IV-ACS Investigators. Troponin and C-reactive protein have different relations to subsequent mortality and myocardial infarction after acute coronary syndrome: a GUSTO-IV substudy. J Am Coll Cardiol. 2003;41(6):916-924.

5. Morrow DA, de Lemos JA, Sabatine MS, Antman EM. The search for a biomarker of cardiac ischemia. Clin Chem. 2003;49(4):537-539.

6. Pearson TA, Mensah GA, Alexander, RA, et al; Centers for Disease Control and Prevention; American Heart Association. Markers of inflammation and cardiovascular disease: application to clinical and public health practice: a statement for healthcare professionals from the Centers for Disease Control and Prevention and the American Heart Association. Circulation. 2003;107(3):499-511.

7. Vasan RS. Biomarkers of cardiovascular disease: molecular basis and practical considerations. Circulation. 2006;113(19):2335-2362.

8. Apple FS, Wu AH, Mair J, et al; Committee on Standardization of Markers of Cardiac Damage of the IFCC. Future biomarkers for detection of ischemia and risk stratification in acute coronary syndrome. Clin Chem. 2005;51(5):810-824.

9. Morrow DA, Braunwald E. Future of biomarkers in acute coronary syndromes: moving toward a multimarker strategy. Circulation. 2003;108(3):250-252.

10. Fuster V, Badimon L, Badimon JJ, Chesebro JH. The pathogenesis of coronary artery disease and the acute coronary syndromes. $N$ Engl J Med. 1992;326(4):242-250.
11. Ross R. Atherosclerosis - an inflammatory disease. $N$ Engl J Med. 1999;340(2):115-126.

12. Harris TB, Ferrucci L, Tracy RP, et al. Association of elevated interleukin-6 and C-reactive protein levels with mortality in elderly. Am J Med. 1999;106(5):506-512.

13. Beck BC, Weintraub WS, Alexander RW. Elevation of C-reactive protein in "active" coronary artery disease. Am J Cardiol. 1990;65(3): $168-172$.

14. de Beer FC, Hind CR, Fox KM, Allan RM, Maseri A, Pepys MB. Measurement of serum $\mathrm{C}$-reactive protein concentration in myocardial ischemia and infarction. Br Heart J. 1982;47(3):239-243.

15. Liuzzo G, Biasucci LM, Gallimore JR, et al. The prognostic value of $\mathrm{C}$-reactive protein and serum amyloid A protein in severe unstable angina. N Engl J Med. 1994;331(7):417-424.

16. Ridker PM, Hennekens CH, Buring JE, Rifai N. C-reactive protein and other markers of inflammation in the prediction of cardiovascular disease in women. N Engl J Med. 2000;342(12):836-843.

17. Ridker PM, Rifai N, Clearfield M, et al; Air Force/Texas Coronary Atherosclerosis Prevention Study Investigators. Measurement of C-reactive protein for the targeting of statin therapy in the primary prevention of acute coronary events. N Engl J Med. 2001;344(26): 1959-1965.

18. Ridker PM, Glynn RJ, Hennekens CH. C-reactive protein adds to the predictive value of total and HDL cholesterol in determining risk of first myocardial infarction. Circulation. 1998;97(20):2007-2011.

19. Chew DP, Bhatt DL, Robbins MA, et al. Incremental prognostic value of elevated baseline C-reactive protein among established markers of risk in percutaneous coronary intervention. Circulation. 2001;104(9): 992-997.

20. Heeschen C, Hamm CW, Bruemmer J, Simoons ML. Predictive value of $\mathrm{C}$-reactive protein and troponin $\mathrm{T}$ in patients with unstable angina: a comparative analysis. CAPTURE Investigators. Chimeric c7E3 Antiplatelet Therapy in Unstable angina Refractory to standard treatment trial. J Am Coll Cardiol. 2000;35(6):1535-1542.

21. Lindahl B, Toss H, Siegbahn A, Venge P, Wallentin L. Markers of myocardial damage and inflammation in relation to long-term mortality in unstable coronary artery disease. FRISC Study Group. Fragmin during Instability in Coronary Artery Disease. N Engl J Med. 2000;343(16):1139-1147.

22. Biasucci LM, Liuzzo G, Grillo RL, et al. Elevated levels of C-reactive protein at discharge in patients with unstable angina predict recurrent instability. Circulation. 1999;99(7):855-860.

23. de Winter RJ, Bholasingh R, Lijmer JG, et al. Independent prognostic value of $\mathrm{C}$-reactive protein and troponin I in patients with unstable angina or non-Q-wave myocardial infarction. Cardiovasc Res. 1999;42(1):240-245.

24. Kuller LH, Tracy RP, Shaten J, Meilahn EN. Relation of C-reactive protein and coronary artery disease in the MRFIT nested case-control study. Multiple Risk Factor Intervention Trial. Am J Epidemiol. 1996;144(6):537-547.

25. Noh HJ, Kwon NH, Joo SB. Severity of coronary atherosclerosis; influence of metabolic syndrome risk factor clustering and hs-CRP. Korean Circ J. 2006;36(12):802-808.

26. Doo YC, Park WJ, Park SH, et al. The optimal timing to measure C-reactive protein to predict cardiac events in patients with unstable angina. Korean Circ J. 2001;31(3):290-296.

27. Kim TI, Chae SC, Yang DH, et al. Short-term prognostic value of CRP in the patients with acute coronary syndrome. Korean Circ J. 2000;30(11): 1387-1394.

28. Haverkate F, Thompson SG, Pyke SD, Gallimore JR, Pepys MB. Production of $\mathrm{C}$-reactive protein and risk of coronary events in stable and unstable angina. European Concerted Action on Thrombosis and Disabilities Angina Pectoris Study Group. Lancet. 1997;349(9050):462-466.

29. Rossi E, Biasucci LM, Citterio F, et al. Risk of myocardial infarction and angina in patients with severe peripheral vascular disease: predictive role of C-reactive protein. Circulation. 2002;105(7):800-803.

30. Rolph MS, Zimmer S, Bottazzi B, Garlanda C, Mantovani A, Hansson GK. Production of the long pentraxin PTX3 in advanced atherosclerotic plaques. Arterioscler Thromb Vasc Biol. 2002;22(5):e10-e14. 
31. Garlanda C, Bottazzi B, Bastone A, Mantovani A. Pentraxins at the crossroads between innate immunity, inflammation, matrix deposition, and female fertility. Annu Rev Immunol. 2005;23:337-366.

32. Peri G, Introna M, Corradi D, et al. PTX3, a prototypical long pentraxin, is an early indicator of acute myocardial infarction in humans. Circulation. 2000;102(6):636-641.

33. Latini R, Maggioni AP, Peri G, et al; Lipid Assessment Trial Italian Network (LATIN) Investigators. Prognostic significance of the long pentraxin PTX3 in acute myocardial infarction. Circulation. 2004;110(16):2349-2354.

34. Dubin R, Li Y, Ix JH, Shlipak MG, Whooley M, Peralta CA. Associations of pentraxin-3 with cardiovascular events, incident heart failure, and mortality among persons with coronary artery disease: data from the Heart and Soul Study. Am Heart J. 2012;163(2): 274-279.

35. Jenny NS, Arnold AM, Kuller LH, Tracy RP, Psaty BM. Associations of pentraxin 3 with cardiovascular disease and all-cause death: the Cardiovascular Health Study. Arterioscler Thromb Vasc Biol. 2009;29(5): 594-599.

36. Lee DH, Jeon HK, You JH, et al. Pentraxin 3 as a novel marker predicting congestive heart failure in subjects with acute coronary syndrome. Korean Circ J. 2010;40(8):370-376.

37. Alam N, Khan HI, Chowdhury AW, et al. Elevated serum homocysteine level has a positive correlation with serum cardiac troponin I in patients with acute myocardial infarction. Bangladesh Med Res Counc Bull. 2012;38(1):9-13.

38. Washio T, Nomoto K, Watanabe I, Tani S, Nagao K, Hirayama A. Relationship between plasma homocysteine levels and congestive heart failure in patients with acute myocardial infarction. Homocysteine and congestive heart failure. Int Heart J. 2011;52(4):224-228.

39. Agoşton-Coldea L, Mocan T, Seicean A, Gatfossé M, Rosenstingl S. The plasma homocysteine concentrations and prior myocardial infarction. Rom J Intern Med. 2010;48(1):65-72.

40. Kosuge M, Ebina T, Ishikawa T, et al. Serum amyloid A is a better predictor of clinical outcomes than C-reactive protein in non-ST-segment elevation acute coronary syndromes. Circ J. 2007;71(2):186-190.

41. Katayama T, Nakashima H, Takagi C, et al. Prognostic value of serum amyloid A protein in patients with acute myocardial infarction. Circ J. 2005;69(10):1186-1191.

42. Johnson BD, Kip KE, Marroquin OC, et al; National Heart, Lung, and Blood Institute. Serum amyloid A as a predictor of coronary artery disease and cardiovascular outcome in women: the National Heart, Lung, and Blood Institute-Sponsored Women's Ischemia Syndrome Evaluation (WISE). Circulation. 2004;109(6):726-732.

43. Tousoulis D, Papageorgiou N, Androulakis E, Briasoulis A, Antoniades C, Stefanadis C. Fibrinogen and cardiovascular disease: genetics and biomarkers. Blood Rev. 2011;25(6):239-245.

44. Reinhart WH. Fibrinogen - marker or mediator of vascular disease? Vasc Med. 2003;8(3):211-216.

45. Coppola G, Rizzo M, Abrignani MG, et al. Fibrinogen as a predictor of mortality after acute myocardial infarction: a forty-two-month follow-up study. Ital Heart J. 2005;6(4):315-322.

46. Yayan J. Erythrocyte sedimentation rate as a marker for coronary heart disease. Vasc Health Risk Manag. 2012;8:219-223.

47. Erikssen G, Liestøl K, Bjørnholt JV, Stormorken H, Thaulow E, Erikssen J. Erythrocyte sedimentation rate: a possible marker of atherosclerosis and a strong predictor of coronary heart disease mortality. Eur Heart J. 2000;21(19):1614-1620.

48. Timmer JR, Ottervanger JP, Hoorntje JC, et al; Zwolle Myocardial Infarction study group. Prognostic value of erythrocyte sedimentation rate in ST segment elevation myocardial infarction: interaction with hyperglycaemia. J Intern Med. 2005;257(5):423-429.

49. van der Laan AM, Hirsch A, Robbers LF, et al. A proinflammatory monocyte response is associated with myocardial injury and impaired functional outcome in patients with ST-segment elevation myocardial infarction: monocytes and myocardial infarction. Am Heart J. 2012;163(1):57-65. e2.
50. Tousoulis D, Androulakis E, Papageorgiou N, et al. From atherosclerosis to acute coronary syndromes: the role of soluble CD40 ligand. Trends Cardiovasc Med. 2010;20(5):153-164.

51. Setianto BY, Hartopo AB, Achadiono DN, Gharini PP. Association between levels of circulating soluble CD40 ligand on admission and in-hospital events among acute coronary syndrome patients. Acta Med Indones. 2011;43(2):82-87.

52. Jefferis BJ, Whincup PH, Welsh P, et al. Prospective study of circulating soluble CD40 ligand concentrations and the incidence of cardiovascular disease in a nested prospective case-control study of older men and women. J Thromb Haemost. 2011;9(8):1452-1459.

53. Abramson N, Melton B. Leukocytosis: basics of clinical assessment. Am Fam Physician. 2000;62(9):2053-2060.

54. Grau AJ, Boddy AW, Dukovic DA, et al; CAPRIE Investigators. Leukocyte count as an independent predictor of recurrent ischemic events. Stroke. 2004;35(5):1147-1152.

55. Akhtar N, Adil MM, Ahmed W, Habib-ur-Rehman, Shahs MA. The role of leukocyte counts in patients with unstable angina pectoris or myocardial infarction; prognostic significance and correlation with plasma brain natriuretic peptide (BNP) levels. J Pak Med Assoc. 2011;61(1):51-54.

56. Björkbacka H, Lavant EH, Fredrikson GN, et al. Weak associations between human leucocyte antigen genotype and acute myocardial infarction. J Intern Med. 2010;268(1):50-58.

57. Meissner J, Irfan A, Twerenbold R, et al. Use of neutrophil count in early diagnosis and risk stratification of AMI. Am J Med. 2011;124(6): 534-542.

58. Maugeri N, Rovere-Querini P, Evangelista V, et al. An intense and short-lasting burst of neutrophil activation differentiates early acute myocardial infarction from systemic inflammatory syndromes. PLoS ONE. 2012;7(6):e39484.

59. Murasaki S, Murasaki K, Tanoue K, Kawana M, Hagiwara N, Kasanuki H. Circulating platelet and neutrophil activation correlates with the clinical course of unstable angina. Heart Vessels. 2007;22(6): 376-382.

60. Schaub N, Reichlin T, Meune C, et al. Markers of plaque instability in the early diagnosis and risk stratification of acute myocardial infarction. Clin Chem. 2012;58(1):246-256.

61. Baldus S, Heeschen C, Meinertz T, et al; CAPTURE Investigators. Myeloperoxidase serum levels predict risk in patients with acute coronary syndromes. Circulation. 2003;108(12):1440-1445.

62. Brennan ML, Penn MS, Van Lente F, et al. Prognostic value of myeloperoxidase in patients with chest pain. $N$ Engl J Med. 2003;349(17):1595-1604

63. Stankovic S, Asanin M, Majkic-Singh N, et al. The usefulness of myeloperoxidase in prediction of in-hospital mortality in patients with ST-segment elevation myocardial infarction treated by primary percutaneous coronary intervention. Clin Lab. 2012;58(1-2):125-131.

64. Morrow DA, Wang Y, Croce K, et al. Myeloid-related protein 8/14 and the risk of cardiovascular death or myocardial infarction after an acute coronary syndrome in the Pravastatin or Atorvastatin Evaluation and Infection Therapy: Thrombolysis in Myocardial Infarction (PROVE IT-TIMI 22) trial. Am Heart J. 2008;155(1):49-55.

65. Bonaca MP, Scirica BM, Sabatine MS, et al. Prospective evaluation of pregnancy-associated plasma protein-a and outcomes in patients with acute coronary syndromes. J Am Coll Cardiol. 2012;60(4):332-338.

66. Iversen KK, Dalsgaard M, Teisner AS, et al. Pregnancy-associated plasma protein-A, a marker for outcome in patients suspected for acute coronary syndrome. Clin Biochem. 2010;43(10-11):851-857.

67. Khan DA, Sharif MS, Khan FA. Diagnostic performance of highsensitivity troponin $\mathrm{T}$, myeloperoxidase, and pregnancy-associated plasma protein A assays for triage of patients with acute myocardial infarction. Korean J Lab Med. 2011;31(3):172-178.

68. Kobayashi N, Hata N, Kume N, et al. Soluble lectin-like oxidized low-density lipoprotein receptor-1 as an early biomarker for ST elevation myocardial infarction: time-dependent comparison with other biomarkers: time-dependent comparison with other biomarkers. Circ J. 2011;75(6):1433-1439. 
69. Hayashida K, Kume N, Murase T, et al. Serum soluble lectin-like oxidized low-density lipoprotein receptor-1 levels are elevated in acute coronary syndrome: a novel marker for early diagnosis. Circulation. 2005;112(6):812-818.

70. Dohi T, Miyauchi K, Okazaki S, et al. Decreased circulating lipoproteinassociated phospholipase A2 levels are associated with coronary plaque regression in patients with acute coronary syndrome. Atherosclerosis. 2011;219(2):907-912.

71. Garg PK, McClelland RL, Jenny NS, et al. Association of lipoprotein-associated phospholipase $\mathrm{A}(2)$ and endothelial function in the Multi-Ethnic Study of Atherosclerosis (MESA). Vasc Med. 2011;16(4): 247-252.

72. Heart Protection Study Collaborative Group. Lipoprotein-associated phospholipase $\mathrm{A}_{2}$ activity and mass in relation to vascular disease and nonvascular mortality. J Intern Med. 2010;268(4):348-358.

73. Mallat Z, Lambeau G, Tedgui A. Lipoprotein-associated and secreted phospholipases $\mathrm{A}_{2}$ in cardiovascular disease: roles as biological effectors and biomarkers. Circulation. 2010;122(21):2183-2200.

74. Gonçalves I, Edsfeldt A, Ko NY, et al. Evidence supporting a key role of Lp-PLA2-generated lysophosphatidylcholine in human atherosclerotic plaque inflammation. Arterioscler Thromb Vasc Biol. 2012;32(6):1505-1512.

75. Falcone C, Lucibello S, Mazzucchelli I, et al. Galectin-3 plasma levels and coronary artery disease: a new possible biomarker of acute coronary syndrome. Int J Immunopathol Pharmacol. 2011;24(4):905-913.

76. López-Mejías R, García-Bermúdez M, González-Juanatey C, et al. Lack of association of IL6R rs2228145 and IL6ST/gp130 rs2228044 gene polymorphisms with cardiovascular disease in patients with rheumatoid arthritis. Tissue Antigens. 2011;78(6):438-441.

77. van Diepen S, Roe MT, Lopes RD, et al. Baseline NT-proBNP and biomarkers of inflammation and necrosis in patients with ST-segment elevation myocardial infarction: insights from the APEX-AMI trial. J Thromb Thrombolysis. 2012;34(1):106-113.

78. Fan ZX, Hua Q, Li YP, Liu RK, Yang Z. Interleukin-6, but not soluble adhesion molecules, predicts a subsequent mortality from cardiovascular disease in patients with acute ST-segment elevation myocardial infarction. Cell Biochem Biophys. 2011;61(2):443-448.

79. Cavusoglu E, Marmur JD, Hojjati MR, et al. Plasma interleukin-10 levels and adverse outcomes in acute coronary syndrome. Am J Med. 2011;124(8):724-730.

80. Welsh P, Murray HM, Ford I, et al; PROSPER Study Group. Circulating interleukin-10 and risk of cardiovascular events: a prospective study in the elderly at risk. Arterioscler Thromb Vasc Biol. 2011;31(10): 2338-2344.

81. Jafarzadeh A, Esmaeeli-Nadimi A, Nough H, Nemati M, Rezayati MT. Serum levels of interleukin (IL)-13, IL-17 and IL-18 in patients with ischemic heart disease. Anadolu Kardiyol Derg. 2009;9(2): 75-83.

82. Jafarzadeh A, Nemati M, Rezayati MT. Serum levels of interleukin (IL)-27 in patients with ischemic heart disease. Cytokine. 2011;56(2): $153-156$

83. Dhillon OS, Narayan HK, Quinn PA, Squire IB, Davies JE, Ng LL. Interleukin 33 and ST2 in non-ST-elevation myocardial infarction: comparison with Global Registry of Acute Coronary Events Risk Scoring and NT-proBNP. Am Heart J. 2011;161(6):1163-1170.

84. Kunes P, Holubcova Z, Kolackova M, Krejsek J. Interleukin-33, a novel member of the IL-1/IL-18 cytokine family, in cardiology and cardiac surgery. Thorac Cardiovasc Surg. 2010;58(8):443-449.

85. Suchanek H, Myśliwska J, Siebert J, et al. High serum interleukin-18 concentrations in patients with coronary artery disease and type 2 diabetes mellitus. Eur Cytokine Netw. 2005;16(3):177-185.

86. Patti G, Mega S, Pasceri V, et al. Interleukin-1 receptor antagonist levels correlate with extent of myocardial loss in patients with acute myocardial infarction. Clin Cardiol. 2005;28(4):193-196

87. Devaux Y, Bousquenaud M, Rodius S, et al. Transforming growth factor $\beta$ receptor 1 is a new candidate prognostic biomarker after acute myocardial infarction. BMC Med Genomics. 2011;4:83.
88. Oemrawsingh RM, Lenderink T, Akkerhuis KM, et al; CAPTURE investigators. Multimarker risk model containing troponin-T, interleukin 10, myeloperoxidase and placental growth factor predicts long-term cardiovascular risk after non-ST-segment elevation acute coronary syndrome. Heart. 2011;97(13):1061-1066.

89. Dizdarević-Hudić L, Kusljugić Z, Baraković F, et al. Correlation between interleukin 6 and interleukin 10 in acute myocardial infarction. Bosn J Basic Med Sci. 2009;9(4):301-306.

90. Mälarstig A, Eriksson P, Hamsten A, Lindahl B, Wallentin L, Siegbahn A. Raised interleukin-10 is an indicator of poor outcome and enhanced systemic inflammation in patients with acute coronary syndrome. Heart. 2008;94(6):724-729.

91. Paakkanen R, Lokki ML, Seppänen M, Tierala I, Nieminen MS, Sinisalo J. Proinflammatory HLA-DRB1*01-haplotype predisposes to ST-elevation myocardial infarction. Atherosclerosis. 2012;221(2): $461-466$

92. Chang LT, Yuen CM, Sun CK, et al. Role of stromal cell-derived factor-1alpha, level and value of circulating interleukin-10 and endothelial progenitor cells in patients with acute myocardial infarction undergoing primary coronary angioplasty. Circ J. 2009;73(6): 1097-1104.

93. Eitel I, Blase P, Adams V, et al. Growth-differentiation factor 15 as predictor of mortality in acute reperfused ST-elevation myocardial infarction: insights from cardiovascular magnetic resonance. Heart. 2011;97(8):632-640.

94. Schaub N, Reichlin T, Twerenbold R, et al. Growth differentiation factor-15 in the early diagnosis and risk stratification of patients with acute chest pain. Clin Chem. 2012;58(2):441-449.

95. Harutyunyan MJ, Mathiasen AB, Winkel P, et al; CLARICOR Trial Group. High-sensitivity C-reactive protein and N-terminal pro-B-type natriuretic peptide in patients with stable coronary artery disease: a prognostic study within the CLARICOR trial. Scand J Clin Lab Invest. 2011;71(1):52-62.

96. Pemberton CJ, Siriwardena M, Kleffmann T, et al. First identification of circulating prepro-A-type natriuretic peptide (preproANP) signal peptide fragments in humans: initial assessment as cardiovascular biomarkers. Clin Chem. 2012;58(4):757-767.

97. Berton G, Cordiano R, Palmieri R, Cavuto F, Buttazzi P, Palatini P. Comparison of $\mathrm{C}$-reactive protein and albumin excretion as prognostic markers for 10-year mortality after myocardial infarction. Clin Cardiol. 2010;33(8):508-515.

98. Kim JS, Hwang HJ, Ko YG, et al. Ischemia-modified albumin: is it a reliable diagnostic and prognostic marker for myocardial ischemia in real clinical practice? Cardiology. 2010;116(2):123-129.

99. Wudkowska A, Goch J, Goch A. Ischemia-modified albumin in differential diagnosis of acute coronary syndrome without ST elevation and unstable angina pectoris. Kardiol Pol. 2010;68(4):431-437.

100. Kavsak PA, Hill SA, Bhanich Supapol W, Devereaux PJ, Worster A. Biomarkers for predicting serious cardiac outcomes at 72 hours in patients presenting early after chest pain onset with symptoms of acute coronary syndromes. Clin Chem. 2012;58(1):298-302.

101. Haas B, Serchi T, Wagner DR, et al. Proteomic analysis of plasma samples from patients with acute myocardial infarction identifies haptoglobin as a potential prognostic biomarker. J Proteomics 2011;75(1):229-236

102. Charpentier S, Ducassé JL, Cournot M, et al. Clinical assessment of ischemia-modified albumin and heart fatty acid-binding protein in the early diagnosis of non-ST-elevation acute coronary syndrome in the emergency department. Acad Emerg Med. 2010;17(1):27-35.

103. Bali L, Cuisset T, Giorgi R, et al. Prognostic value of ischaemiamodified albumin in patients with non-ST-segment elevation acute coronary syndromes. Arch Cardiovasc Dis. 2008;101(10): 645-651.

104. Holm J, Ravn J, Ingemann Hansen S. Urinary excretion of alpha1microglobulin and albumin in acute myocardial infarction. Correlation with plasma concentrations of troponin I and C-reactive protein. Scand J Urol Nephrol. 2006;40(4):339-344. 
105. Ataoğlu HE, Yilmaz F, Uzunhasan I, et al. Procalcitonin: a novel cardiac marker with prognostic value in acute coronary syndrome. $J$ Int Med Res. 2010;38(1):52-61.

106. Bektas F, Soyuncu S, Gunduz I, Basarici I, Akbas H, Eken C. The value of procalcitonin, a novel inflammatory marker, in the diagnosis of myocardial infarction and evaluation of acute coronary syndrome patients. J Emerg Med. 2011;41(5):524-530.

107. Kelly D, Khan SQ, Dhillon O, et al. Procalcitonin as a prognostic marker in patients with acute myocardial infarction. Biomarkers. 2010;15(4):325-331.

108. Kafkas N, Venetsanou K, Patsilinakos S, et al. Procalcitonin in acute myocardial infarction. Acute Card Care. 2008;10(1):30-36.

109. Schiopu A, Hedblad B, Engström G, Struck J, Morgenthaler NG, Melander O. Plasma procalcitonin and the risk of cardiovascular events and death: a prospective population-based study. J Intern Med. 2012;272(5):484-491.
110. Tan K, Lu S, Chen Y, et al. CXC chemokine ligand 16 as a prognostic marker in patients with intermediate coronary artery lesions: a 2-year follow-up study. Tohoku J Exp Med. 2011;223(4):277-283.

111. Ng LL, Khan SQ, Narayan H, Quinn P, Squire IB, Davies JE. Proteinase 3 and prognosis of patients with acute myocardial infarction. Clin Sci. 2011;120(6):231-238.

112. Palikhe A, Sinisalo J, Seppänen M, et al. Serum complement C3/C4 ratio, a novel marker for recurrent cardiovascular events. Am J Cardiol. 2007;99(7):890-895.

113. Witkowska AM. Soluble ICAM-1: a marker of vascular inflammation and lifestyle. Cytokine. 2005;31(2):127-134.

\section{Publish your work in this journal}

Vascular Health and Risk Management is an international, peerreviewed journal of therapeutics and risk management, focusing on concise rapid reporting of clinical studies on the processes involved in the maintenance of vascular health; the monitoring, prevention and treatment of vascular disease and its sequelae; and the involvement of metabolic disorders, particularly diabetes. This journal is indexed on PubMed Central and MedLine. The manuscript management system is completely online and includes a very quick and fair peer-review system, which is all easy to use. Visit http://www.dovepress.com/ testimonials.php to read real quotes from published authors. 